\title{
Why Do Election Results Change After Election Day? The "Blue Shift" in California Elections
}

\author{
Yimeng Li ${ }^{1}$, Michelle Hyun ${ }^{1}$, and R. Michael Alvarez ${ }^{1}$ \\ California Institute of Technology
}

June 23, 2021

${ }^{1}$ California Institute of Technology, Division of the Humanities and Social Sciences, 1200 E. California Blvd., Pasadena, CA 91125, USA.

Emails: yimeng.li@caltech.edu,mhyun@caltech.edu, andrma@caltech.edu.

Corresponding author: Yimeng Li, California Institute of Technology, Division of the Humanities and Social Sciences, 1200 E. California Blvd., Pasadena, CA 91125, USA.

Email: yimeng.li@caltech.edu.

Replication materials for this paper are located at https://rmichaelalvarez.github.io/PRQ-Blue-Shift/ 


\begin{abstract}
The counting of votes in contemporary American elections is usually not completed on Election Night. There has been an increasing tendency for vote shares to shift toward Democratic candidates after Election Day in general elections (Foley and Stewart III, 2020), in particular in recent U.S. elections. Leveraging important snapshots of precinct-level election returns and precinct-level demographic and political composition from Orange County, California, we conduct the first full-fledged analysis of the potential drivers of vote share shifts. Utilizing an original large-scale post-election survey and unique snapshots of individual-level administrative records, we also provide the first analysis of the characteristics of voters whose ballots were tallied later versus earlier in the process. Far from being anomalous, our results indicate that the shifts are consistent with underlying precinct voter compositions and the order of precinct and mail ballot processing at the individual level in accordance with election administration practices. We find the same driving forces in North Carolina and Colorado, and discuss the consequences of the "Blue Shift" for public concerns about election integrity as states push policy changes regarding access to voting by mail.
\end{abstract}

Keywords: American elections, "Blue Shift," voting by mail 


\section{Introduction}

On Election night, November 6, 2018, Republican candidate Young Kim thought she had won California's 39th U.S. House election. She had a lead of three percentage points over her Democratic opponent Gil Cisneros with over 150,000 votes counted. But weeks after Election Day, once all of the ballots in the 39th Congressional race from Orange, Los Angeles, and San Bernardino Counties were verified and tabulated, Kim learned that the outcome had flipped parties and that Cisneros was the winner.

Young Kim is not the first candidate to assume that the reported election results on Election Night (or those reported early in the morning of the day after the election) are an accurate indication of the final outcome of the race. She is also not alone in witnessing that the vote shares, and even the House seats, slipped away during days after the election. Nationwide, in the U.S. House elections in 2018, vote shares shifted toward Democratic candidates in 156 congressional districts — with a magnitude of $2 \%$ or more in 63 districts — and toward Republican candidates in just 34 seats, as shown in Figure $1 .{ }^{1}$ Six Democratic candidates ultimately won while trailing the morning after Election Day (five out of 30 toss-up seats labeled by the New York Times on a five-point competitiveness scale), and three more barely lost (by less than $0.1 \%$ ) after shifts in the vote shares in their favor. As increasing numbers of ballots are tabulated in many jurisdictions, the vote margins in recent elections are often observed to shift towards favoring Democratic candidates, which researchers have called the "Blue Shift" (Foley and Stewart III, 2020).

Candidates, like Young Kim, and their supporters, may wonder how an election can flip from one party's candidate to another party's candidate if not for voter fraud. Young Kim, and Mimi Walters in California's 45th congressional district race in Orange County — another candidate witnessing the vote share shifting toward her Democratic opponent — both alleged voter fraud is 
behind the vote share shifts. ${ }^{2}$ Walters told supporters in an email that she needed donations to stop Democrats "from overturning the will of the voters." Kim, meanwhile, said that all the uncounted ballots must "nearly match" the results of those already tallied and "[a]nything falling significantly outside of those percentages could reflect foul play." Voters who cast ballots to losing candidates are already more likely to believe votes were counted improperly at local and national levels (Sances and Stewart III, 2015), and we believe seeing election results "flip" is likely to exacerbate the problem. ${ }^{3}$ Without a good understanding of why the "Blue Shift" occurs, stakeholders and voters will raise questions regarding election integrity and subsequently lose confidence in the legitimacy of elections. $^{4}$

When elections are close, a phenomenon like the electoral "Blue Shift" may lead some to question the integrity of the American election system. In the spotlight are voting by mail and provisional voting, since regular polling place ballots are almost always counted on Election Night. House of Representatives Speaker Paul Ryan commented on California, where voting by mail was prevalent in November 2018, "California just defies logic to me," and "[w]e were only down 26 seats the night of the election, and three weeks later we lost basically every contested California race. This election system they have, I can't begin to understand what ballot harvesting is."

As votes began to be tallied during the 2020 Presidential election, shifting reported vote totals in many battleground states led to erroneous claims of voting fraud, unfortunately raising concerns about election integrity. For example, in Pennsylvania, the very early vote totals reported before 10 pm Eastern trended in favor of Biden, but after about $11 \mathrm{pm}$ Eastern when about $40 \%$ of the vote had been tallied, Trump began to take the lead. ${ }^{6}$ From there, Trump's lead grew steadily, but by the time about $75 \%$ of the ballots were tabulated in the morning of November 4 , Biden began to close the gap, and Biden eventually won Pennsylvania the state by about 80,000 votes. During this period of shifting vote margins, Trump repeatedly took to social media, implying that these changing vote 
totals were somehow due to voter fraud, claims that were repeatedly struck down by the courts as having no factual support. Despite the lack of evidence, these allegations received a great deal of attention on social media and in various media outlets, and these episodes may lead to a loss of confidence in the integrity of elections in the United States in the minds of some citizens and voters. As states push policy changes regarding access to voting by mail after the 2020 Presidential election, a thorough analysis of the "Blue Shift" is crucial to seeing the whole picture of the partisan consequences, or the lack thereof, of voting by mail, a point we will return in the discussion section.

Despite media coverage and questions raised by stakeholders regarding this phenomenon, shifts in vote shares after Election Day have received scarce scholarly attention. In this paper, we study the phenomenon in depth using unique granular data from Orange County, California - a large, diverse county with 1.5 million registered voters and several closely contested races. We first document the vote share shifts toward Democratic candidates in the county across congressional districts and precincts. We then establish the positive correlation between the magnitude of shifts in vote shares and the volume of mail ballots received close to or on Election Day and provisional ballots, two types of ballots typically counted after Election Day. We test hypotheses regarding the association between the vote share shifts and precinct demographic and political composition. We find, among other results, precincts with a higher proportion of young voters and non-white voters had a larger "Blue Shift." To understand the patterns we observe across precincts, we test our hypotheses about the association between voter characteristics and casting types of ballots that are counted later in the process using survey data and individual-level administrative records. Our results indicate that voters who are young, non-white, not registered with the two major parties, or are voting for the first time are more likely to cast such ballots. Finally, to explore the generalizability of our findings to other counties and states, we examine data from North Carolina and Colorado. Results from the analyses strongly suggest the presence of the same underlying drivers. 
We make two major contributions. First, cross-state analyses in previous studies feature only a small number of observations and covariates and suffer from confounders such as election laws that are left unaccounted for. Leveraging snapshots of precinct-level election returns as ballots were tallied and information on precinct-level demographics and registration characteristics, we conduct the first fullfledged precinct-level analysis that includes more than a thousand precincts in a large and diverse county. As a result, our analysis has an order of magnitude greater statistical power in testing our hypotheses relative to past studies, while keeping any variables concerning election administration practices constant. Second, utilizing snapshots of individual-level administrative records, we provide an individual-level analysis of the characteristics of voters whose ballots were tallied later versus earlier in the process. This analysis is buttressed by a similar examination of an independent source of data from our post-election survey of voters. The difference in voter composition regarding ballots processed at different timing during the canvass elucidates the mechanics behind vote share shifts observed at aggregate levels. 


\section{What Happens After Election Day}

Technological advances have made ballot counting and transmission of election results faster than ever. In many states, including California, soon after polls close, election officials release results from early-voting ballots and mail ballots that have been processed before Election Day, followed by regular ballots cast on Election Day as precincts report them. Major cable networks, news radio, and other media organizations receive these results from the Associated Press correspondents stationed at local government offices and data feeds provided by local governments as soon as they become available and make projections on most races. As a result, for voters following Election Day coverage on television, radio, Internet, or through morning newspapers, it may appear that elections are mostly over except for a few close contests by the end of Election Night. This perception masks the reality that a significant fraction of ballots are counted after Election Day, especially in states like California, where voting by mail and provisional ballots is common.

While the ballot tabulation process begins immediately after polls close with vote-by-mail ballots received and processed before Election Day, mail ballots received close to and on Election Day through the mail or at the precincts are tabulated after Election Day. ${ }^{7}$ California law requires voteby-mail ballots postmarked on or before Election Day and received by county elections officials no later than three days after Election Day must be processed and counted if verified (California Senate Bill No.29, 2014). ${ }^{8}$ The volume of ballots received late in the election cycle can be quite large. For example, in the November 2018 General Election in Orange County, 320,000 (47\%) mail ballots were added to the tally after Election Day, and those dropped off at polling places on Election Day alone amounted to nearly 200,000..$^{9}$ Processing such large numbers of mail ballots is difficult and complicated. Even sorting these mail ballots so that they are organized, all facing the same direction, in mail trays is a time-consuming task and county elections officials need to verify 
voter records and determine if ballots have been cast by eligible voters. In Orange County, it took 51 hours in total (and around 30 hours for the sorting operation alone) before all votes cast this way are tallied and reported in November 2018. ${ }^{10}$

One of the earliest papers on absentee voting noted that in California's initial implementation of liberalized voting by mail, there were partisan skews in how the absentee balloting broke by party (Patterson and Caldeira, 1985). This was particularly pronounced in the first implementation of liberalized voting by mail, and the partisan skew diminished considerably in subsequent elections (but did not disappear). The authors noted that the partisan skews in voting by mail could arise because of demographic differences in the segments of the electorate who voting by mail appeals to, or it could arise from strategic behavior by party elites who may try to persuade their party's constituencies to use the voting by mail process. More recent research finds little support for the hypothesis that voting by mail has partisan implications (Alvarez, Levin and Sinclair, 2012; Thompson et al., 2020). The literature on voting by mail, however, typically does not distinguish between by-mail voters who cast their ballots early in the election cycle and those that cast their mail ballot later.

While regular polling place ballots are almost always counted on Election Night, provisional ballots - ballots cast by voters whose names do not appear on the precinct roster-are the other category of ballots that are processed and counted after Election Day. ${ }^{11}$ The Help America Vote Act (HAVA) of 2002 established nationwide the right for a voter to cast a provisional ballot if their name is not listed on the registration list, though California's provisional voting statutes have been in effect since $1984 .^{12}$ Many voters end up voting provisionally in each election. In the November 2018 General Election in Orange County, nearly 160,000 provisional ballots were cast, with over 100,000 eventually added to the tally after Election Day. ${ }^{13}$ Provisional ballots are typically counted after Election Day, as are late-arriving vote-by-mail ballots, because county elections officials need 
to confirm that those ballots were cast by eligible or registered voters who did not already vote in the election. ${ }^{14}$ In Orange County, the processing of provisional ballots started more than a week after Election Day in November 2018. ${ }^{15}$ While there is little research on which types of voters are more likely to cast a provisional ballot, there are indications that young voters and non-white voters might be more likely to cast provisional ballots, as well as those who have recently moved or have recently registered (Alvarez and Hall, 2009; Merivaki and Smith, 2016, 2020).

Figure 2 shows the official canvass in Orange County for the November 2018 General Election as the process of ballot tabulation progressed. Consistent with common election administration practices, immediately after the polls close, the Orange County Registrar of Voters (OCROV) released results from 360,000 early-returned mail ballots that had already been processed and prepared for tabulation before Election Day. The time between poll closing and the wee hours of Wednesday is almost exclusively devoted to the counting of precinct votes, with results from 280,000 such ballots reported as soon as they became available. Ballot tabulation continued on Wednesday with mail ballots that are dropped off at polling places, drop box locations, or that arrive at county elections offices on Election Day. Then, with the final batches of mail ballots counted and posted in the tally, the county election officials reorient their effort to processing provisional ballots. Finally, the official canvass concluded on November 30, 2018, when all valid votes had been counted, and OCROV certified the official results. 


\section{Explaining the Blue Shift}

Despite media coverage and questions raised by stakeholders regarding this phenomenon, shifts in vote shares after Election Day have received scarce scholarly attention. Foley (2013) and Foley and Stewart III (2020) are the only exceptions that we are aware of. Foley (2013) examined state-level vote share shifts for presidential races between 1960 and 2012. Foley and Stewart III (2020) conducted a cross-state analysis to study the association between the shift in state vote shares with the number of provisional ballots, the number of mail ballots and Obama's vote share in 2012, and a case study of Virginia with overtime votes broken down by ballot types for statewide elections from 2008 to 2014. Following Foley and Stewart III (2020), we call vote share shifts towards Democratic party and Republican party candidates after Election Day "Blue Shifts" and "Red Shifts," respectively.

Our first two hypotheses concern the volume of mail ballots that are returned close to or on Election Day and provisional ballots (we collect all hypotheses in a list in the Online Appendix). While our substantive understanding of election administration practices strongly suggests that a large number of such ballots is necessary for the emergence of a large shift in vote shares, the dearth of established evidence in the literature prompts us to test these hypotheses before subsequent analyses.

We first consider provisional ballots. The trend of the "Blue Shift" starting in 2004 and accelerating in 2008 and 2012 is consistent with the timing of the enactment of the Help America Vote Act (HAVA) in 2002, which requires provisional ballots nationally (Foley, 2013). Furthermore, the number of counted provisional ballots is positively associated with the magnitude of the "Blue Shift" across states in 2012 (Foley and Stewart III, 2020). We hypothesize that precincts with a larger percentage of polling place ballots that are counted later in the process on average have a larger “Blue Shift” after Election Day (Hypothesis 1a). ${ }^{16}$ 
We now turn our attention to mail ballots. California and Washington saw an increase in both the percentage of absentee voters and the magnitude of the "Blue Shifts" since 1992 (Foley, 2013). Moreover, these two states and Oregon, known for their heavy reliance on voting by mail in recent years, are the states where Obama gained the most from post-Election-Day shifts (Foley, 2013). The fraction of voters voting by mail, however, is not correlated with the magnitude of the "Blue Shifts" across states in 2012 (Foley and Stewart III, 2020). In this paper, we make a distinction between mail ballots processed before Election Day and those that are received close to or after Election Day and get counted later in the process. This distinction is important as only mail ballots counted after Election Day contribute to shifts in vote shares, and these ballots may disproportionately come from certain demographic groups even when mail ballots as a whole do not. We hypothesize that the percentage of permanent absentee voters in a precinct is not correlated with the magnitude of the "Blue Shift," but precincts with a larger percentage of mail ballots that are counted later in the process on average have a larger "Blue Shift" after Election Day (Hypothesis 1b). ${ }^{17}$

A large number of votes that are counted after Election Day is necessary but not sufficient for a large shift in vote shares towards one party to emerge. Another condition that needs to be met is the composition of such votes differing significantly from votes that are counted before or on Election Day. ${ }^{18}$

Theoretically, the "calculus of voting" has been used to explain why certain segments of the electorate do not participate in electoral politics; for young voters and voters of color, in particular, the costs of voting can be significantly greater than for older and white voters. (Riker and Ordeshook, 1968; Rosenstone and Wolfinger, 1978; Leighley and Nagler, 2013). Convenience voting reforms (like voting by mail) and voting fail-safe procedures (like provisional balloting) have been promoted to help high-cost voters exercise their franchise, so we expect to see that high-cost voters may be 
more likely to vote by mail, to return their ballots at the last minute, and to use provisional voting (Rosenstone and Wolfinger, 1978; Foley, 2013; Shino, Suttmann-Lea and Smith, 2021).

Media reports and the few academic studies on the topic suggest that higher-cost voters, especially young voters and voters of color, are more likely to encounter problems with registration and end up casting provisional ballots (Alvarez and Hall, 2009; Merivaki and Smith, 2016). The Cooperative Congressional Election Survey (CCES) identifies 146 and 176 provisional voters in their 2018 and 2016 surveys, respectively. In those data, while only a very small fraction of CCES respondents voted provisionally, we find age and racial disparities that provide a basis for our study. In terms of age, $0.34 \%$ of 2018 CCES respondents below the age of 45 reported casting provisional ballots, compared to $0.17 \%$ of respondents older than 45 . Regarding race, among non-white 2018 CCES respondents, $0.36 \%$ voted provisionally, whereas the number is $0.20 \%$ for white respondents. The disparities are even larger for the 2016 survey. ${ }^{19}$ Thus, we hypothesize that young and non-white voters are more likely to cast polling place ballots that are counted later in the process (Hypothesis 2a).

The timing of absentee voters returning their mail ballots does not attract as much attention as provisional ballots and is not asked in the CCES, but it determines when these ballots are counted. We turn to the Survey of the Performance of American Elections (SPAE), which identifies 60 respondents returning their mail ballots on Election Day among 2,038 absentee voters nationally. The number is again very small, but we see disparities in terms of age and race/ethnicity: among 2016 SPAE respondents below the age of 45 who voted by mail, $6.8 \%$ returned the ballot on Election Day, while the number is $1.5 \%$ for respondents older than 45 . As for race/ethnicity, $5.0 \%$ of non-white 2016 SPAE respondents who voted by mail returned the ballot on Election Day, compared to $2.5 \%$ of white respondents. We hypothesize that young and non-white voters are more likely to cast mail ballots that are counted later in the process (Hypothesis $\mathbf{2 b}$ ). 
Besides demographics, party identification and registration is another major factor associated with casting provisional ballots and the timing of returning mail ballots. During an election cycle, registered Democrats and Republicans are more likely to participate in their party primary elections than voters not affiliated with the two major parties. Should there be problems with their registration, many of the issues would have already been resolved by the time of the general election, reducing the chance of having to vote provisionally. Moreover, voters registered with the Democratic Party or the Republican Party often vote for their party nominees in a general election with little hesitation, instead of waiting until Election Day to decide, given the importance of partisanship as a voting cue or heuristic (Campbell et al., 1980; Bartels, 2000). This tendency should increase their likelihood of returning their mail ballots early compared to other voters. Therefore, we hypothesize that voters registered with the two major parties are less likely to cast polling place ballots or mail ballots that are counted later in the process (Hypothesis $2 \mathbf{c})$.

Hypotheses regarding individual voters have implications at the aggregate level. Given that young and non-white voters are more likely to cast polling place or mail ballots that are counted later in the process (Hypotheses 2a-b), and the well-established pattern that these voters are more likely to cast their ballots for Democratic candidates, we predict that precincts with a larger percentage of young voters and non-white voters on average have a larger "Blue Shift" after Election Day (Hypothesis 3a). Registered Republican voters are less likely to vote for Democratic candidates, and their ballots tend to be counted earlier (Hypothesis 2c), contributing to the "Blue Shift'.' Registered Democratic voters, meanwhile, are more likely to vote for the Democratic party nominees, and these ballots are also more likely to be counted earlier (Hypothesis 2c), counteracting the "Blue Shift." This logic yields the prediction that precincts with a larger percentage of registered Democratic (Republican) voters on average have a smaller (larger) "Blue Shift” after Election Day (Hypothesis 3b). We, however, also note a competing logic that yields the opposite prediction. Foley and Stewart III 
(2020) find that bluer states on average had a larger "Blue Shift" in 2012. Extrapolate this finding to the precinct level and viewing party registration as a proxy for the partisanship of precincts would yield an alternative prediction that precincts with a larger percentage of registered Democratic (Republican) voters on average have a larger (smaller) "Blue Shift" after Election Day (Hypothesis 3c). 


\section{Data and Measurement}

We empirically test these hypotheses using granular data from Orange County, California. The Orange County Registrar of Voters (OCROV) provided us with snapshots of their voter registration and voting history databases. ${ }^{20}$ Besides data availability, there are several reasons to believe Orange County is a good laboratory for studying post-Election Day shifts in vote shares. First, Orange County is a large and diverse county. Orange County is the fifth largest voting jurisdiction in the United States, with over 2 million voting-eligible citizens and 1.6 million registered voters (California Secretary of State 2018). The Census Bureau's recent data estimates that $21 \%$ of Orange County's population is Asian and 34\% of the population is of Hispanic, Latino, or Spanish descent (United States Census Bureau 2018). The large and diverse nature of the county permits significant variation across precincts in terms of demographic and political composition while keeping election administration practices fixed. Second, there are seven congressional districts in Orange County, at least four of which were highly contested in the 2018 midterm elections (CA-39, 45, 48, and 49). Even a modest-sized shift in vote shares could see these seats "flip" after Election Day, and several losing candidates raised questions about such shifts during the post-election canvass period in 2018 .

To construct our measure of post-Election Day shifts in vote shares, we use information from general election result reports from OCROV. OCROV releases detailed reports containing up-to-date election returns approximately every half an hour on Election Night and every business day during the post-election canvass. Included in these reports is the vote count for each candidate running for federal, state, and local offices in each precinct based on ballots tallied by the time of the release. 
Let $D_{p, i, r}, R_{p, i, r}$, and $T_{p, i, r}$ denote the vote counts for the Democratic candidate, the Republican candidate, and the total number of ballots cast, respectively, in race $r$ by the end of Election Night in precinct $p$ (subscript $i$ stands for "initial"). Let $D_{p, f, r}, R_{p, f, r}$, and $T_{p, f, r}$ denote the final vote totals (subscript $f$ stands for "final"). Then we obtain the shift in vote shares in race $r$ in precinct $p$ as follows:

$$
\text { Shift }_{p, r}=\frac{D_{p, f, r}-R_{p, f, r}}{T_{p, f, r}}-\frac{D_{p, i, r}-R_{p, i, r}}{T_{p, i, r}}
$$

where term $\left(D_{p, i, r}-R_{p, i, r}\right) / T_{p, i, r}$ corresponds to the vote share difference from the last report on Election Night, and term $\left(D_{p, f, r}-R_{p, f, r}\right) / T_{p, f, r}$ corresponds to the difference according to the final certified results. ${ }^{21}$ Since the first report after Election Night is not released until late afternoon on the day after the election, the aggregate vote share differences based on the last report on Election Night are the most relevant quantities for media coverage throughout the day after Election. ${ }^{22}$

In order to analyze the precinct-level correlates of shifts in vote shares, we calculate the demographic and political composition of precincts using information from the Orange County voter registration database. OCROV maintains its voter registration database containing every registered voter's name, address, party registration, permanent absentee status, and other fields that a voter filled out when registered to vote. We aggregate individual voters' information to construct variables encoding the distribution of voters' age, gender, race/ethnicity, party registration, and permanent absentee status for each precinct. ${ }^{23}$

For the individual-level analysis to uncover the mechanics behind the shifts in vote shares at aggregate levels, we use information from two separate sources: a large-scale post-election survey of registered voters in Orange County and snapshots of the Orange County voting history database. Our survey data consist of nearly 7,000 complete responses from over 500,000 email invitations to all registered voters in Orange County with email addresses in the voter file. Among the respondents, 
around 4,000 voters cast their ballots by mail (see the paper's Supplemental Material for details about the survey). We restrict attention to confirmed voters and focus on the question most pertinent to this research: timing of returning mail ballots. ${ }^{24}$ For voting-by-mail voters, we asked: To the best of your memory, when was your ballot returned? Response options included On Election Day, A few days before Election Day, The week before Election Day, More than a week before Election Day, and I don't remember. This question was intended to elicit whether a respondent cast a type of ballots that would have been processed later versus earlier. The survey also included standard batteries regarding voter demographics and other individual characteristics, which we use to study their association with the timing of ballots being counted. We use a standard raking algorithm, which matches sample moments on age, gender, race/ethnicity, party registration, and city of residence to their population counterparts, to produce weights that we use in our statistical analyses to produce representative results. Compared to administrative records, analysis using our survey data features a smaller number of observations but contains a richer set of covariates.

The voting history database contains every registered voter's turnout and method of voting records in past elections. During the post-election canvass, OCROV updates the records for voters once OCROV verifies their identities against the registration records and confirms they have cast their ballots. By comparing different snapshots of this database, we can identify the voters whose ballots are processed earlier versus later. ${ }^{25}$ Combining with information gathered from the voter registration database, we can establish the association between voters' demographics and other registration characteristics and the timing of their ballots being counted.

Figure 3 displays a visualization of the record updating activities OCROV conducted during the canvass following the November 2018 General Election. During the first database maintenance activity after the election, conducted on the second day after Election Day, OCROV updated records for 530,000 voters whose mail ballots had already been processed. Nine days later came the updates 
of records for the remaining voting-by-mail voters and 320,000 polling place voters, with the identities of precinct voters extracted from the Election Day rosters. OCROV then continuously updated the remaining records as they verified and counted provisional ballots from voters who were eligible and did not already vote by mail. While the pattern of maintenance activities of the voting history database tracks the releases of election result reports shown in Figure 2 closely, there are some noticeable but expected differences. Election result reports were released approximately every half an hour on Election Night and every business day during the week after Election Day to facilitate timely public communication, whereas updates of voting records occurred in bulk. It is also a manifestation of the fact that precinct votes were tabulated by machines on Election Night while transferring turnout information from Election Day rosters to the database requires hours of human effort. 


\section{The Blue Shift in Orange County, California}

We saw in Figures 2-3 that a sizable fraction of ballots, including mail ballots returned on Election Day and provisional ballots cast in polling places, were counted after Election Day. The incorporation of these votes led to vote share shifts toward the Democratic party candidates, or the "Blue Shift." We present the vote share shifts in Orange County in the November 2018 General Election in Figure 4 for the gubernatorial race and in Figure A3 in the paper's Supplemental Material for the House races. As Figure 4 shows, while the Republican gubernatorial candidate John H. Cox entertained a6.9\% lead in Orange County at the end of Election Night, it is his Democratic opponent Gavin Newsom who ended up winning more votes among Orange County voters. The "Blue Shift" in the gubernatorial race is also evident across all congressional districts, as the lines in Figure 4 suggest, with the largest magnitudes in congressional districts CA 46 (11.5\%), CA 39 (7.1\%), and CA 45 (6.8\%).

Unlike the governor race in Orange County, where vote share shifts did not change the outcome given the results in other counties, two House seats "flipped" after Election Day. In CA 45, the Republican incumbent Mimi Walters held a 3.3\% lead at the end of Election Night but quickly saw it eroded. By the time all votes had been counted, the Democratic challenger Katie Porter won the seat with $4.0 \%$ more votes. Meanwhile, for the open seat in CA 39, Republican candidate Young Kim's $8.5 \%$ initial lead reduced to only $1.3 \%$ after Election Day in Orange County, which, together with results in Los Angeles and San Bernardino counties, saw Democrat Gil Cisneros taking the seat. As we noted before, both losing candidates raised questions about such shifts.

Before diving into the correlates of the vote share shifts, we break down the county and district level results and compare the vote share differences at the end of Election Night and the canvass (i.e., the certified results) at the precinct level. Figure 5 compares the vote share differences for the 
gubernatorial race in the 2018 General Election in Orange County, and Figure A4 in the paper's Supplemental Material compares the differences for the U.S. House of Representatives races in the same year. As Figure 5 shows, the certified vote share difference (Democratic vote share minus Republican vote share) is larger than the Election Night final for most precincts (89\%), with many by a large percentage, across congressional districts and irrespective of the initial lead or deficit by the Democratic candidate. Importantly, there is a notable amount of variation across precincts, even within a congressional district. We leverage such precinct-level variation and detailed information about each precinct to understand the "Blue Shift" in the next section. 


\section{The Blue Shift, Explained}

\section{Precinct-Level Analysis: Volume of Ballots Counted After Election Day}

We first look at the association between the magnitude of vote share shifts and the volume of mail and polling place ballots counted after Election Day. These associations are shown in the Supplemental Material in Figure A5, and regression tables for all results reported hereafter are also included in the paper's Supplemental Material. Consistent with our substantive understanding of election administration practices, the magnitude of shifts in vote shares is positively correlated with the fraction of voters casting two types of ballots counted later in the process. Regression results in the paper's Supplemental Material indicate that precincts with $20 \%$ more either type of ballots counted later in the process on average had slightly over 1\% larger "Blue Shift," which is both statistically significant and sizable in competitive races.

Figure A5 in the Supplemental Material also clearly indicates that the magnitude of vote share shifts varies substantially for precincts with similar volumes of mail and polling place ballots counted after Election Day. As we argued, a larger fraction of voters casting types of ballots counted later in the process is necessary but not sufficient for the emergence of a larger shift in vote shares. The "Blue Shift" would not occur if these voters were equally or less likely to favor Democratic candidates than voters who mail in their ballots early or cast regular precinct ballots.

\section{Precinct-Level Analysis: Voter Composition}

As we argued, we expect that the magnitude of vote share shifts in different precincts will vary in ways consistent with the demographic and political characteristics of precincts. We investigate the association between the magnitude of vote share shifts and the fraction of voters who are 
young, female, non-white, registered with the major parties, and signed up to be permanent absentee, displayed in Figure 6. Consistent with our hypotheses, more young and non-white voters are associated with larger shifts toward Democratic presidential and gubernatorial candidates in a precinct. All else equal, a 10\% increase in the proportion of young voters and non-white voters translates to a $0.46 \%$ and $0.93 \%$ larger vote share shift, respectively, toward Gavin Newsom, the Democratic candidate for governor in 2018. The same increases correspond to a $0.33 \%$ and $0.45 \%$ larger vote share shift, respectively, toward Hillary Clinton, the Democratic candidate for president in 2016. Different precincts, meanwhile, are very similar in terms of gender composition, as one would expect. The lack of variation in gender composition leads to very noisy estimates regarding the association between the fraction of female voters and the magnitude of vote share shifts, which is evident in Figure 6.

The results regarding party registration are intriguing. In particular, we find strong support for hypothesis $3 b$ that the fraction of registered Republican voters is positively correlated with the magnitude of the "Blue Shift" in a precinct. Holding other factors fixed, a 10\% increase in the proportion of voters registered with the Republican party translates to a $1.84 \%$ and $1.18 \%$ larger vote share shifts toward Democratic candidates, in 2018 and 2016 respectively, for the top-of-the-ballot races. More registered Democratic voters, meanwhile, are also strongly positively associated with a larger "Blue Shift," which is inconsistent with hypothesis $3 b$ but consistent with hypothesis $3 c{ }^{26}$ The same increases correspond to a $1.46 \%$ and $0.95 \%$ "Blue Shift" in these two election cycles. Finally, in contrast to the positive correlation between the magnitude of vote share shifts and the fraction of mail ballots counted after Election Day, the proportion of permanent absentee voters in a precinct is not correlated with vote share shifts toward Democratic candidates. The lack of correlation is in line with our hypothesis, and further analysis in the Online Appendix shows that precincts with a larger percent of permanent vote-by-mail voters do not have a larger 
percent of mail ballots counted after election day on average (they are in fact somewhat smaller). These results highlight the importance of distinguishing between mail ballots that are counted earlier versus later in the process. Finally, we note that all patterns observed in Figure 6 are also present for House of Representative races, albeit slightly smaller in magnitude, as shown in the Supplemental Material.

\section{Voter-Level Analysis: Voter Survey}

Why do we see larger vote share shifts toward Democratic candidates in precincts with more young voters and non-white voters? We argue that these voters are more likely to cast types of ballots that are counted later in the process. This, together with the well-established fact that these voters are more likely to vote for Democratic candidates, would yield the pattern observed in Figure 6. In this and the next section, we empirically test hypotheses regarding these and other demographic and individual characteristics using survey and administrative data.

We start by analyzing responses from surveyed Orange County voting-by-mail voters, with the average marginal effects of various demographic and individual characteristics on returning mail ballots on Election Day instead of earlier from a logistic regression displayed in Figure 7. Consistent with our hypotheses, voters below the age of 45 and non-white voters are more likely to drop off or mail their vote-by-mail ballots on Election Day, which would result in their ballots being counted after Election Day. All else equal, young voters and non-white voters are $11.9 \%$ and $5.7 \%$ more likely to return their mail ballots on Election Day than old voters and white voters, respectively. While not contributing to the variation of vote share shifts across precincts, we also find gender to be associated with the return of mail ballots on Election Day, with female voters $4.4 \%$ more likely to do so. In terms of party registration, we find strong support for our hypothesis that registered Democratic voters tend to cast their votes before Election Day compared to voters 
not affiliated with the two major parties, leaving the election administrators time to count these votes before the polls open. The effect for registered Republican voters is statistically indistinguishable from zero. The coefficient estimates for party registration have larger standard errors given that the variable is trichotomized, especially for the registered Republican voters as there are fewer of them than registered Democratic voters in Orange County and in our survey sample. This reflects a limitation of using survey data compared to administrative records.

Survey data, however, allows us to control for and look at some individual characteristics that are not available in administrative records. While not part of our main hypotheses, we find that voters who follow politics most of the time are $6.1 \%$ more likely to cast their votes before Election Day. While statistically indistinguishable from zero, the signs of the estimates for having a four-year college degree (negative), owning their home (negative), and voting for the first time (positive), are also as expected. These auxiliary results are generally consistent with our understanding of the political engagement of different types of voters.

\section{Voter-Level Analysis: Administrative Records}

We now proceed to analyze administrative records maintained by the OCROV, with the average marginal effects of various demographic and registration characteristics on casting types of ballots counted later in the process from logistic regressions displayed in Figure 8. We separately analyze by-mail voters and in-person voters as the ballot counting processes for these two modes of voting are different. Immediate from Figure 8, the statistical power is an order of magnitude larger compared to the analysis of survey data, as we have over a million voters participating in the November 2018 General Election in Orange County. Regarding age and race, we find young voters and non-white voters are more likely to cast types of ballots that are counted after Election Day. 
Turning to the results regarding party registration, we find strong support for our hypothesis that registering with one of the major parties is negatively associated with casting types of ballots that are counted after Election Day. Holding other factors fixed, registered Democratic and Republican voters are both $2.0 \%$ more likely to return their mail ballots early compared to voters not affiliated with the two major parties. Voters registered with the Democratic Party and the Republican Party are also $2.4 \%$ and $3.4 \%$ less likely, respectively, to cast provisional ballots, the type of polling place ballots counted after all mail and regular precinct ballots are processed. The results are also consistent with the traditional view of partisanship that voters who would register with a party are likely to be strong and committed partisan voters. Finally, also unsurprisingly, first-time Orange County voters tend to return mail ballots close to Election Day or to cast provisional ballots, the latter of which usually indicates some problem with their voter registration. 


\section{Beyond Orange County, California}

So far, we have established the association between various voter characteristics and casting types of ballots that are counted later in the process, using survey data and comprehensive administrative records from Orange County, California. One important question remains: do the driving forces underlying the vote share shifts generalize to other counties and states? Unfortunately, rich data like that from Orange County does not exist for every state, but we are able to provide supportive evidence from North Carolina and Colorado.

While we do not know when a voter returned their mail ballot (unlike Figure 7) or when the ballot was counted in the process (unlike Figure 8), we take advantage of the timing of when election officials received returned mail ballots available in administrative data from North Carolina and Colorado. Figure 9 presents the average marginal effects of various voter characteristics on their mail ballot being received by election officials on or after Election Day. Consistent with the patterns present in Orange County, California, young voters, female voters, and non-white voters are more likely to return their mail ballots close to Election Day so that their mail ballots reach election officials' offices on or after Election Day. Meanwhile, election officials are more likely to receive returned mail ballots from registered Democratic voters and Republican voters before Election Day compared to voters not affiliated with the two major parties, again mirroring the results from Orange County, California.

Differences in election administration practices, geography, and cost of voting by mail lead to dramatically different volumes of mail ballots and provisional ballots in California, North Carolina, and Colorado. A small percentage of voters cast absentee ballots by mail in North Carolina, whereas

Colorado uses a vote-by-mail system exclusively, with California somewhere in between. ${ }^{27}$ The same underlying driving forces have different implications in the magnitude of vote share shifts 
depending on the volume of mail and provisional ballots. The number of voters casting such ballots has been on the rise for the past two decades as many states eased rules on issuing absentee ballots. ${ }^{28}$ Our results shed light on what to expect as states make absentee ballots by mail less accessible and implement other restrictive policies regarding voting following the 2020 presidential election. 


\section{Conclusion and Discussion}

In this paper, we study the drivers of "Blue Shifts" using comprehensive administrative and survey data from a large, diverse jurisdiction — Orange County, California. Our results indicate that voters who are young, non-white, not registered with the two major parties, or are voting for the first time, are more likely to cast the types of ballots that are counted later in the process. As a result, vote share shifts of different magnitudes emerge in precincts in a manner consistent with their underlying demographic and political composition.

Understanding why vote shares shift as vote counting continues after Election Day is a crucial step to addressing the concerns that voters and stakeholders may have after observing the seemingly anomalous phenomenon. There was considerable conversation about these post-election vote tabulation shifts after the recent 2020 Presidential election, for example. Leveraging snapshots of precinct-level electoral returns and individual-level administrative records, our paper is a first attempt at uncovering the mechanism behind the "Blue Shifts." We identify three areas that warrant further investigation to fully understand the extent and the drivers of this phenomenon.

First, future research should continue to explore how well our results generalize to other counties and states as well as future election cycles. While we also confirm that the underlying drivers are present in North Carolina and Colorado, data constraints limit our ability to draw general conclusions at the national level. Our paper, however, provides a template to studying vote share shifts after Election Day on a broader scale. Obtaining the granular data to examine the phenomenon in other jurisdictions may require collaborative efforts with election officials and commercial vendors.

Second, while we empirically establish the demographic and political composition of voters who cast the types of ballots counted later in the process, more research is necessary to understand why these voters return their absentee ballots at the last minute or encounter problems with registration 
that necessitates provisional voting. Past studies have largely focused on why voters turn out or do not turn out in an election, and how voters cast their ballots if they turn out to vote. Future research needs to pay more attention to the timing of voters casting their ballots and its correlation with their vote choices, as well as registration problems that disproportionately affect certain demographics.

Furthermore, using our theory and data, we have argued that the systematic vote share shifts we observed in 2016 and 2018 are largely based on how (and when) different segments of the electorate decide to return their ballots. It is possible that these decisions are facilitated or caused by the mobilization activities of political parties, campaigns, or other voter mobilization organizations. While we believe that the consistency of the post-election shifts across different election contexts (within Orange County in both 2016 and 2018, in other counties and congressional elections in 2018, and of course as identified by other researchers) supports our explanations, the 2020 presidential election seems to have led Democrats and Republicans to take very different approaches for voter mobilization. Whether those same strategies will be taken in future elections we can't predict now, but if parties continue using these mobilization strategies consistently in the future, that should serve to reinforce or even exacerbate the types of post-election shifts towards Democratic candidates that we have studied in our paper.

Third, it remains an open methodological question how to estimate how large a shift in vote shares we should expect in any particular election or contest. Such a methodology would be valuable should candidates or other stakeholders raise serious questions regarding election integrity. Media organizations, meanwhile, may be the other major beneficiary as they seek a sound approach to make projections before state and local officials certify the results. 
While our paper focuses on data collected in 2018 and election cycles prior to that, considering that there was significant debate about post-election vote share shifts after the recent 2020 general elections in November, we note that our research has considerable relevance for those conversations. Given the COVID-19 pandemic, a number of states (like California) shifted to statewide voting by mail in November 2020. The shift to voting-by-mail in the 2020 general election was controversial, as demonstrated by the legal disputes in 2020 battleground states like Wisconsin. ${ }^{29}$ But while recent research has indicated that voting by mail itself may not have partisan consequences (Thompson et al., 2020), it is still the case that the vote-by-mail ballots counted after Election Day in the 2020 presidential election may have the type of partisan consequences we have shown in our research.

While the "Blue Shifts" had already been present in many general elections before the 2020 general election, the dramatic vote share shifts in the 2020 presidential race in several battleground states - for example, in Pennsylvania, as illustrated in the introduction — and the subsequent heated rhetoric during Election 2020 put this phenomenon into the headlines. Our core explanation that the way in which different segments of the electorate cast their votes and the order in which election officials count different types of ballots jointly drove the "Blue Shifts" extends to the 2020 general election.

We should also note the particularities for the 2020 general election amid a pandemic that further contributed to the vote share shifts: historical volume of mail ballots cast, much more widely used ballot drop boxes (where many voters dropped off their ballots close to or on Election Day), and political parties encouraging or discouraging the use of mail ballots. While the long-term impact of these factors remains to be seen, it is concerning that "Blue Shifts" has led some states to propose or implement more restrictive voting laws targeting convenient voting methods. Such laws, if 
enacted, will disproportionately disenfranchise segments of the electorate relying upon these voting methods. 


\section{References}

Alvarez, R. Michael, and Thad E. Hall. 2009. "Provisional Ballots in the 2008 Ohio General Election." Technical report Pew Charitable Trusts, The Center for the States, Provisional Ballots: An Imperfect Solution.

Alvarez, R. Michael, Thad E. Hall, and Morgan H. Llewellyn. 2008. “Are Americans Confident Their Ballots are Counted?" The Journal of Politics 70 (3): 754-66.

Alvarez, R. Michael, Ines Levin, and J. Andrew Sinclair. 2012. “Making Voting Easier: Convenience Voting in the 2008 Presidential Election.” Political Research Quarterly 65 (2): 248-62.

Bartels, Larry M. 2000. "Partisanship and Voting Behavior, 1952-1996." American Journal of Political Science 44 (1): 35-50.

Campbell, Angus, Philip E. Converse, Warren E. Miller, and Donald E. Stokes. 1980. The American Voter. Chicago: University of Chicago Press.

Enamorado, Ted, Benjamin Fifield, and Kosuke Imai. 2019. "Using a Probabilistic Model to Assist Merging of Large-Scale Administrative Records." American Political Science Review 113 (2): $353-71$.

Foley, Edward B. 2013. “A Big Blue Shift: Measuring an Asymmetrically Increasing Margin of Litigation." Journal of Law and Politics 28: 501-46.

Foley, Edward B., and Charles Stewart III. 2020. "Explaining the Blue Shift in Election Canvassing." Journal of Political Institutions and Political Economy 1 (2): 239-65.

Imai, Kosuke, and Kabir Khanna. 2016. "Improving Ecological Inference by Predicting Individual Ethnicity from Voter Registration Records.” Political Analysis 24 (2): 263-72. 
Kim, Seo-young Silvia, Spencer Schneider, and R. Michael Alvarez. 2019. "Evaluating the Quality of Changes in Voter Registration Databases." American Politics Research 48 (6): 670-76.

Leighley, Jan E., and Jonathan Nagler. 2013. Who Votes Now?: Demographics, Issues, Inequality, and Turnout in the United States. Princeton: Princeton University Press.

Merivaki, Thessalia, and Daniel A. Smith. 2016. "Casting and Verifying Provisional Ballots in Florida." Social Science Quarterly 97 (3): 729-47.

Merivaki, Thessalia, and Daniel A. Smith. 2020. "A Failsafe for Voters? Cast and Rejected Provisional Ballots in North Carolina." American Politics Research 73 (1): 65-78.

Mullen, Lincoln. 2018. Gender: Predict Gender from Names Using Historical Data. R package version 0.5.2.

Patterson, Samuel C., and Gregory A. Caldeira. 1985. "Mailing in the Vote: Correlates and Consequences of Absentee Voting." American Journal of Political Science 29 (4): 766-88.

Riker, William H., and Peter C. Ordeshook. 1968. "A Theory of the Calculus of Voting." The American Political Science Review 62 (1): 25-42.

Rosenstone, Steven J., and Raymond E. Wolfinger. 1978. "The Effect of Registration Laws on Voter Turnout." The American Political Science Review 72 (1): 22-45.

Sances, Michael W., and Charles Stewart III. 2015. "Partisanship and Confidence in the Vote Count: Evidence from U.S. National Elections Since 2000.” Electoral Studies 40: 176-88. 
Shino, Enrijeta, Mara Suttmann-Lea, and Daniel A Smith. 2021. "Determinants of Rejected Mail Ballots in Georgia's 2018 General Election." Political Research Quarterly.

Thompson, Daniel M., Jennifer A. Wu, Jesse Yoder, and Andrew B. Hall. 2020. "Universal Vote-byMail has No Impact on Partisan Turnout or Vote Share." Proceedings of the National Academy of Sciences 117 (25): 14052-056.

Udani, Adriano, and David C Kimball. 2018. "Immigrant Resentment and Voter Fraud Beliefs in the U.S. Electorate." American Politics Research 46 (3): 402-33. 
Figure 1: Distribution of Shifts in Vote Shares After Election Day

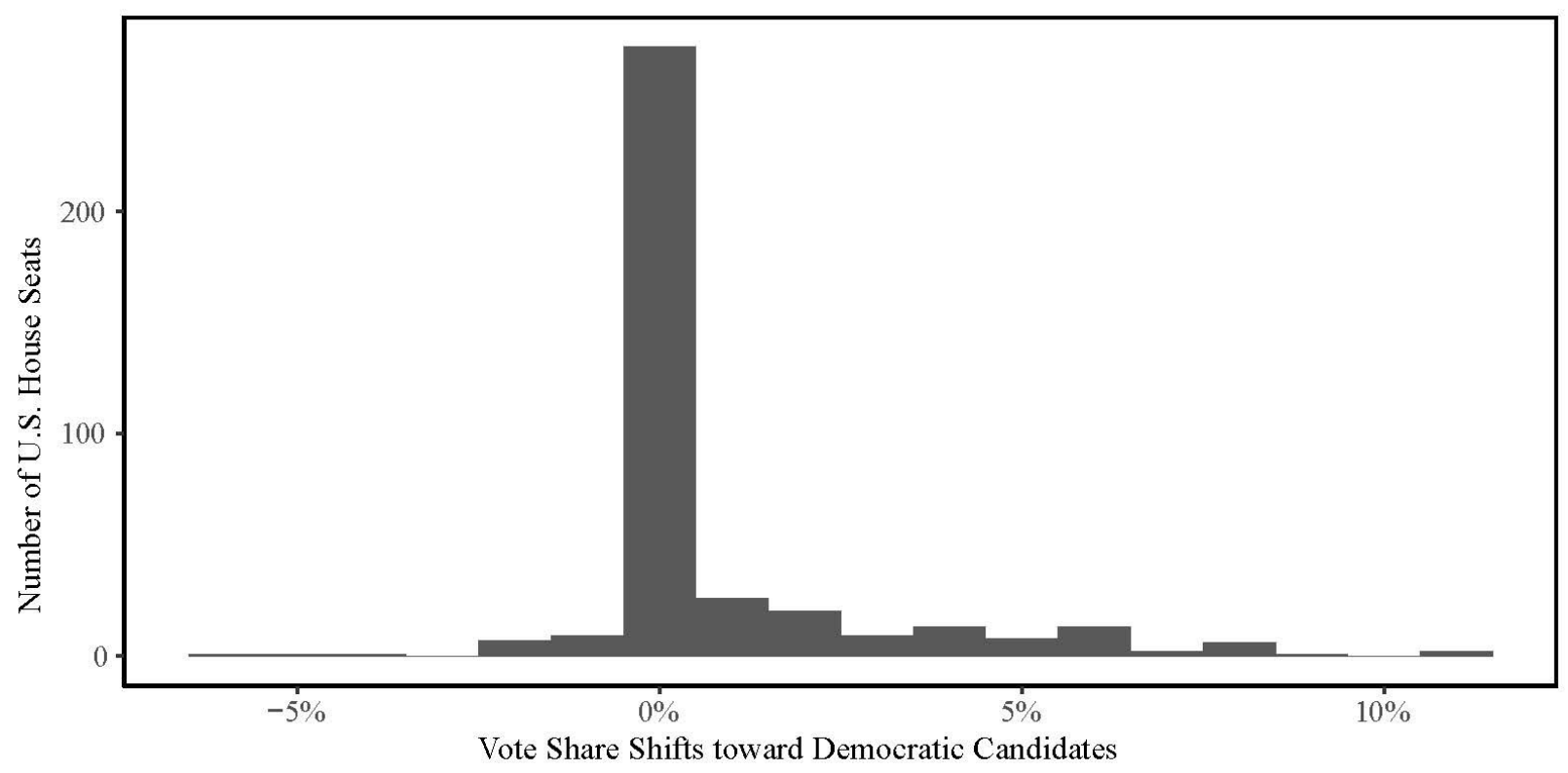

Note: Vote share shifts are calculated as the post-Election-Day changes in the vote share difference between the Democratic candidate and the Republican candidate (see Data and Measurement section for the exact formula). We drop 42 U.S. House seats that were either uncontested or did not have candidates from both parties running for. 
Figure 2: Ballots Tabulated as Canvass Progresses, Orange County, November 2018

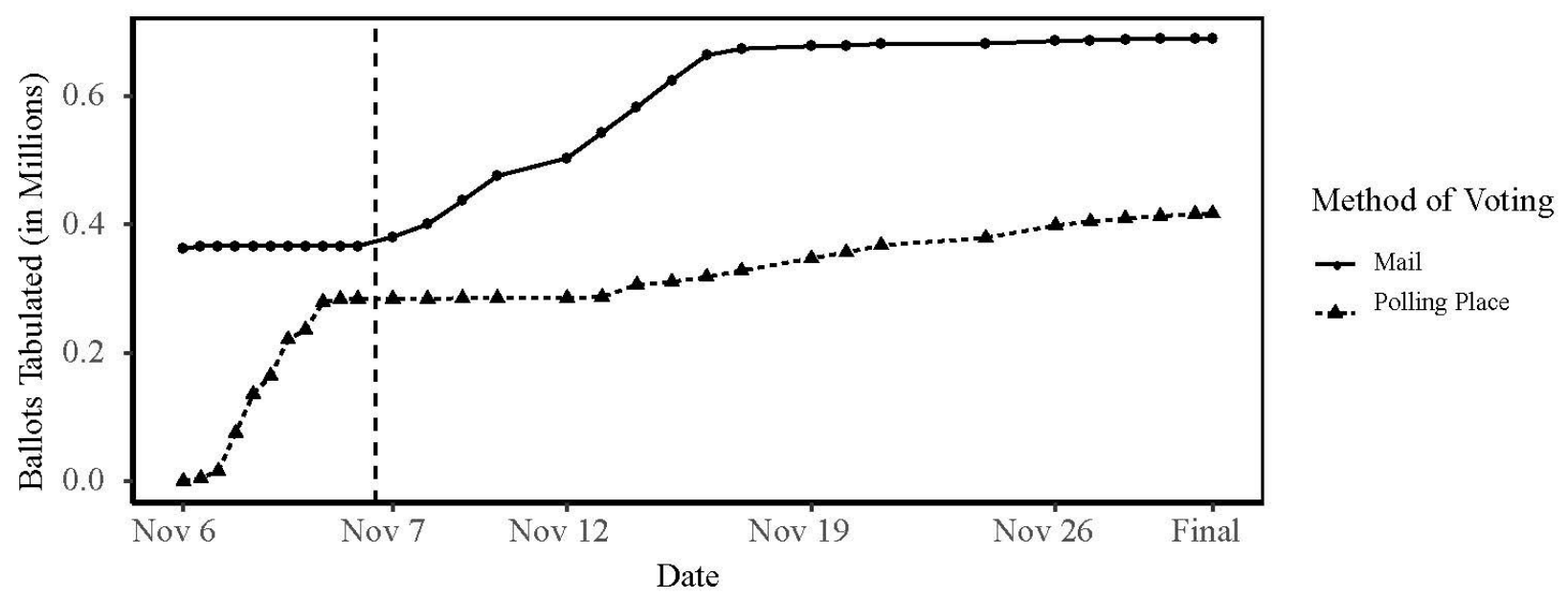

Note: The figure reports the cumulative number of ballots tabulated by the method of voting at different points during the canvass according to election result reports released by the Orange County Registrar of Voters (OCROV). Points to the left of the dashed line correspond to election result reports on Election Night (with the interval between Nov 6 and 7 stretched for better visualization), whereas those to the right refer to reports after Election Day. Polling place ballots include those cast on Election Day as well as during the early voting period. 
Figure 3: Voting Record Updated as Canvass Progresses, Orange County, November 2018

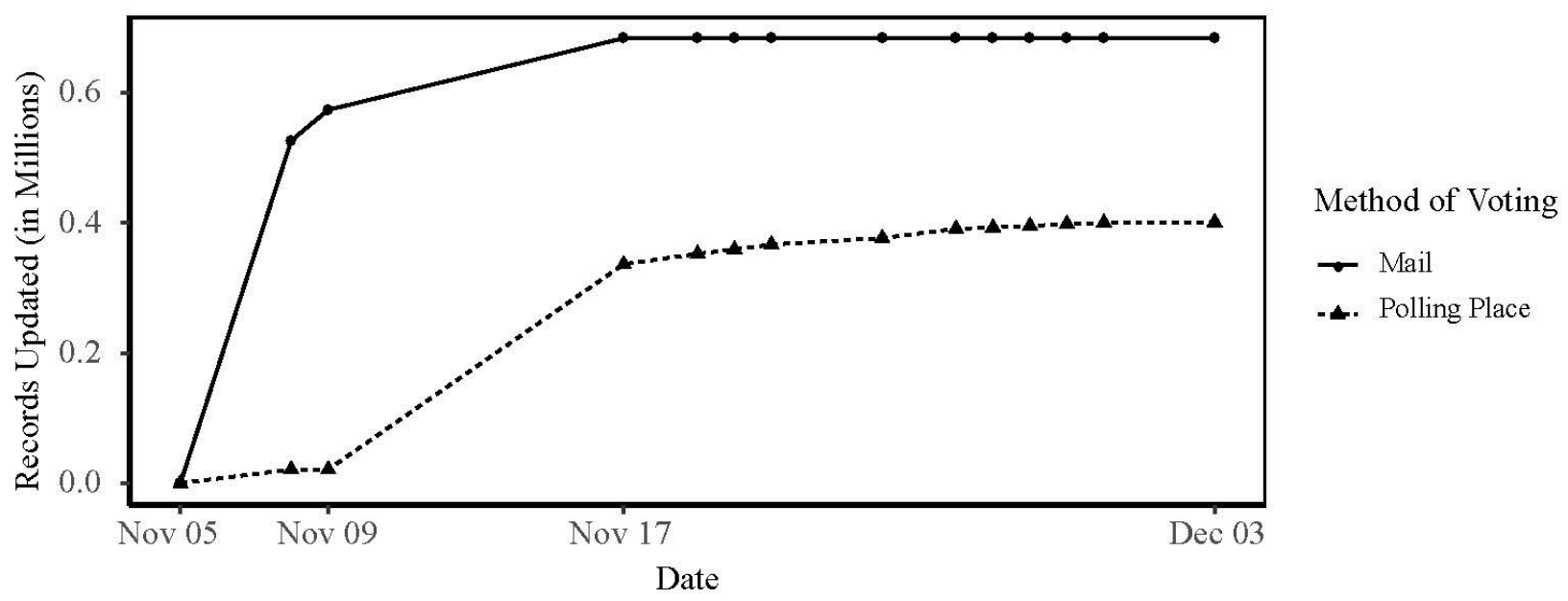

Note: The figure reports the cumulative number of voting records updated by the method of voting at different points during the canvass according to snapshots of the voting history database maintained by OCROV. Polling place ballots include those cast on Election Day as well as during the early voting period. 
Figure 4: Vote Share Shifts as Canvass Progresses, Orange County, November 2018

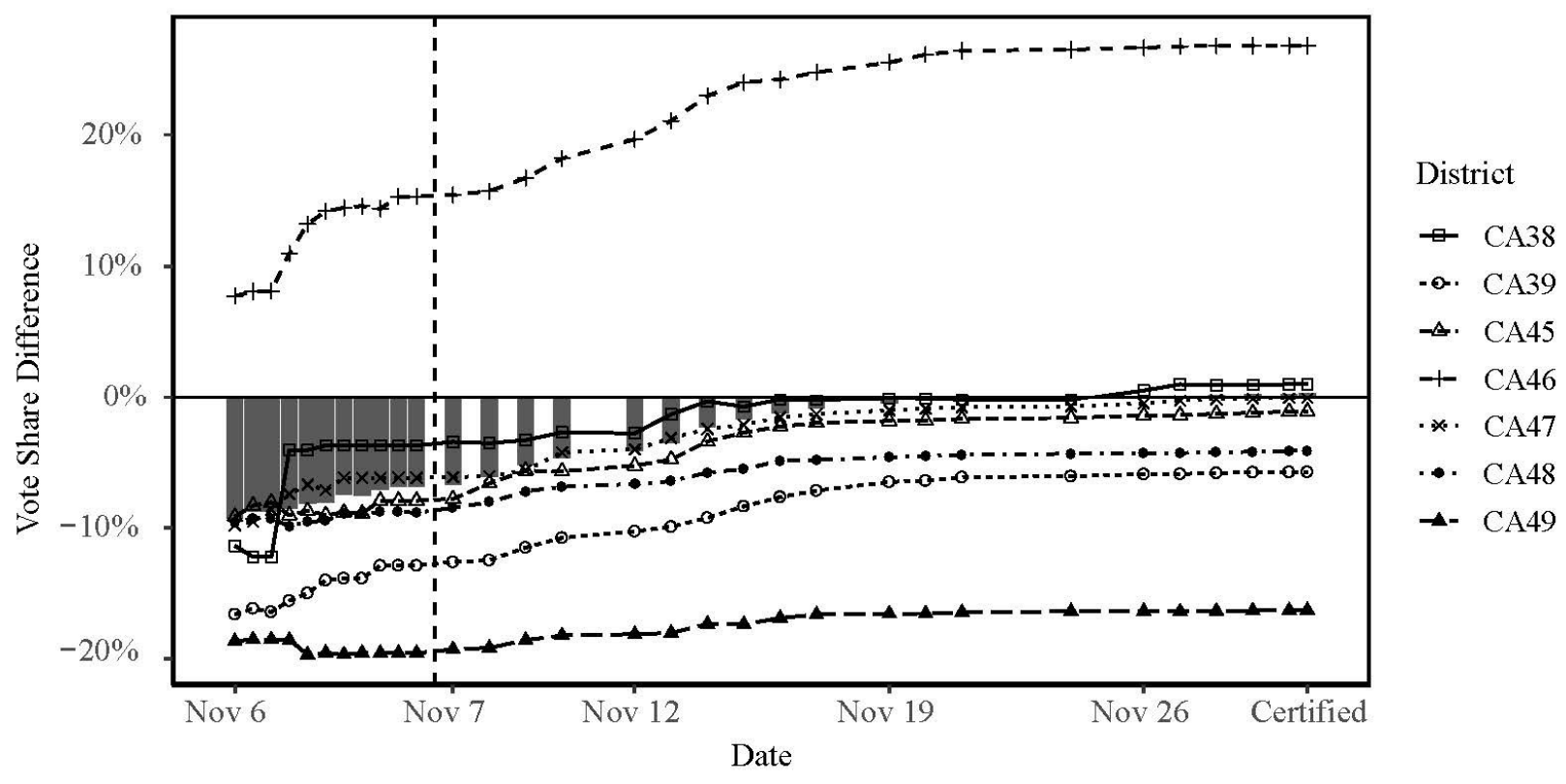

Note: The figure reports the vote share differences (Democratic vote share minus Republican vote share) at different points during the canvass at county level (bars) and district level (lines and points), for the gubernatorial race in Orange County in the November 2018 General Election. 
Figure 5: Election Night Final and Certified Precinct Vote Share Differences, Orange County, November 2018

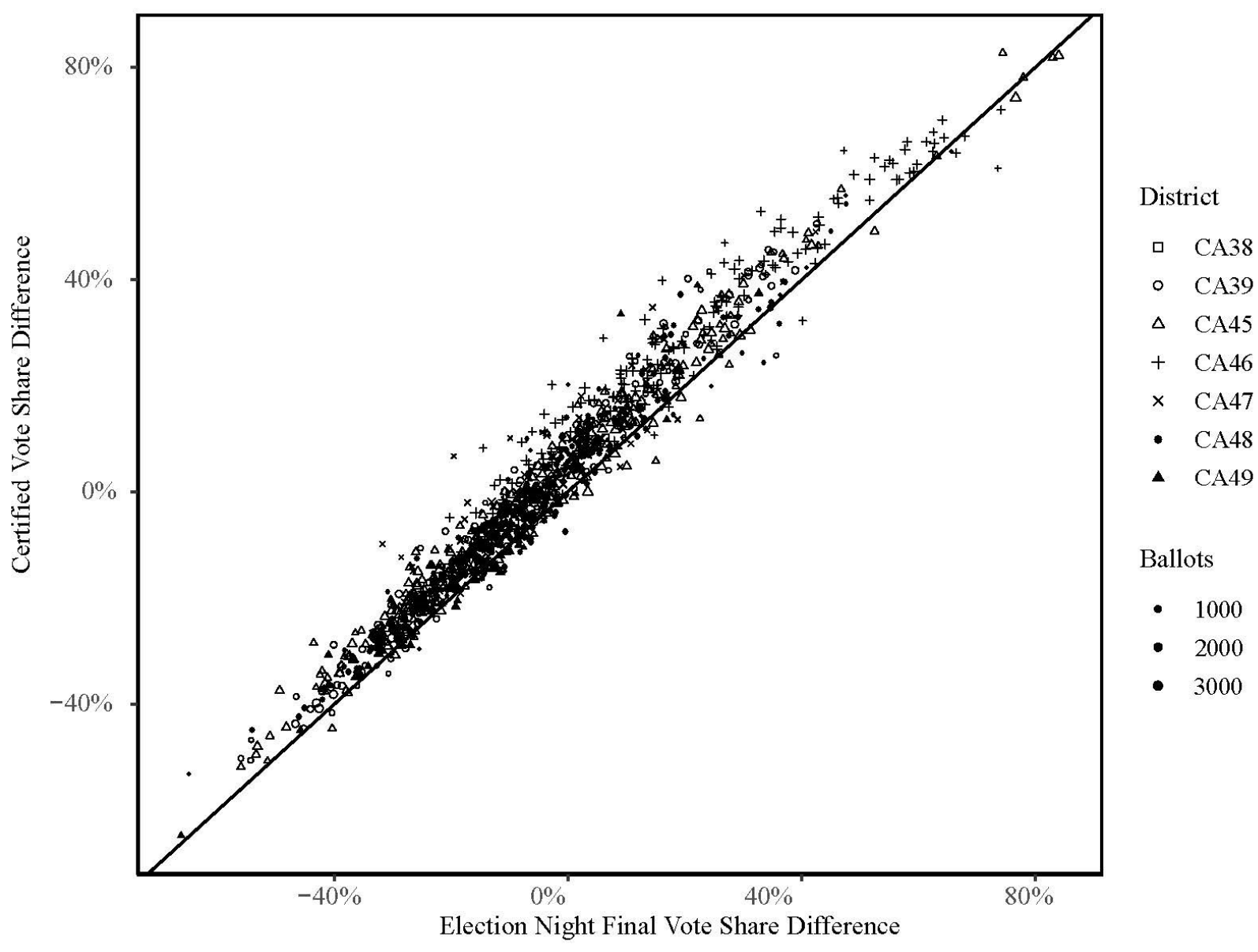

Note: The figure reports the precinct-level vote share differences (Democratic vote share minus Republican vote share) by the end of Election Night and the canvass, for the gubernatorial race in Orange County in the November 2018 General Election ( $\mathrm{N}=1,115$ precincts). The sizes of the points and other shapes are proportional to the number of ballots cast. 
Figure 6: Association Between Voter Composition and Precinct Vote Share Shift

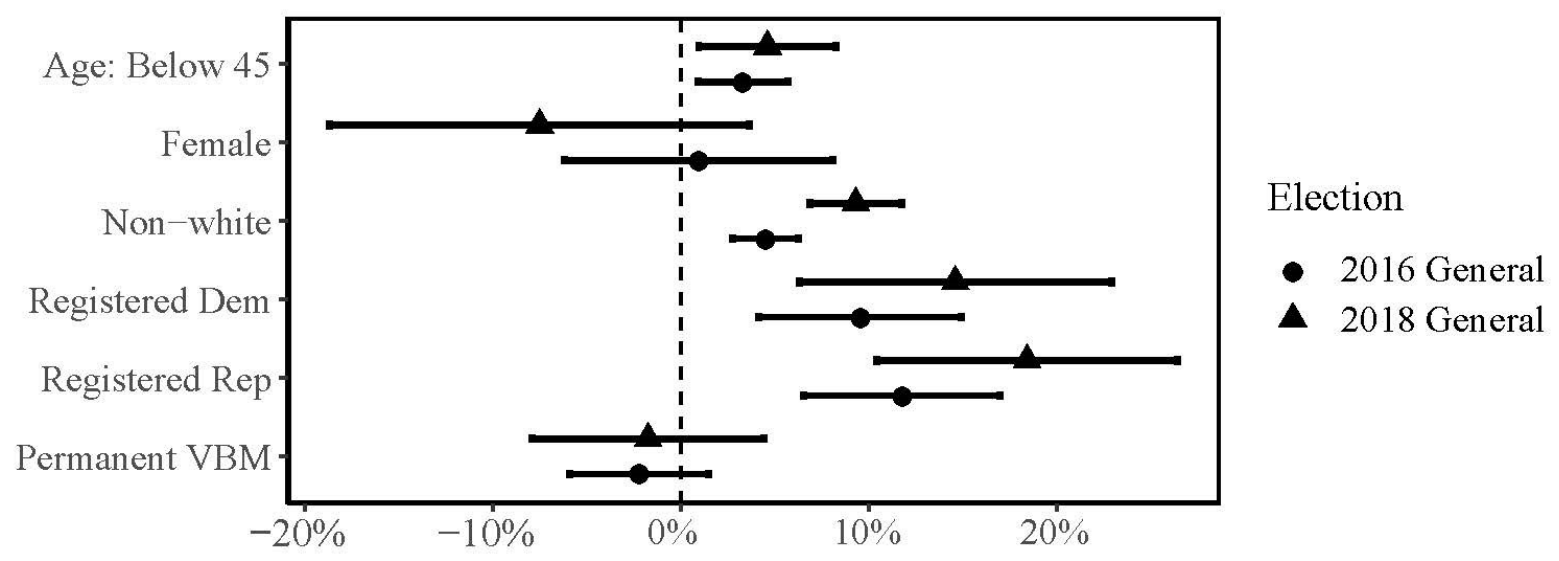

Precinct Vote Share Shift

Note: The figure reports coefficient estimates and 95\% confidence intervals from linear regressions $(\mathrm{N}=$ 1,115 precincts for 2018 General and $\mathrm{N}=1,365$ precincts for 2016 General). Precinct vote share shifts are defined as the changes between the last run during Election canvass and the last run on Election night in precinct-level vote share differences (Democratic candidate vote share minus Republican candidate vote share). Independent variables include the proportion of voters in a precinct who are below the age of 45 , female, non-white, registered with the Democratic party, registered with the Republican party, or signed up for permanent vote-by-mail ballots, as well as Congressional district fixed effects. See Online Appendix Table A2 for the results in a table format. 
Figure 7: Association Between Voter Characteristics and Returning Mail Ballots on Election Day

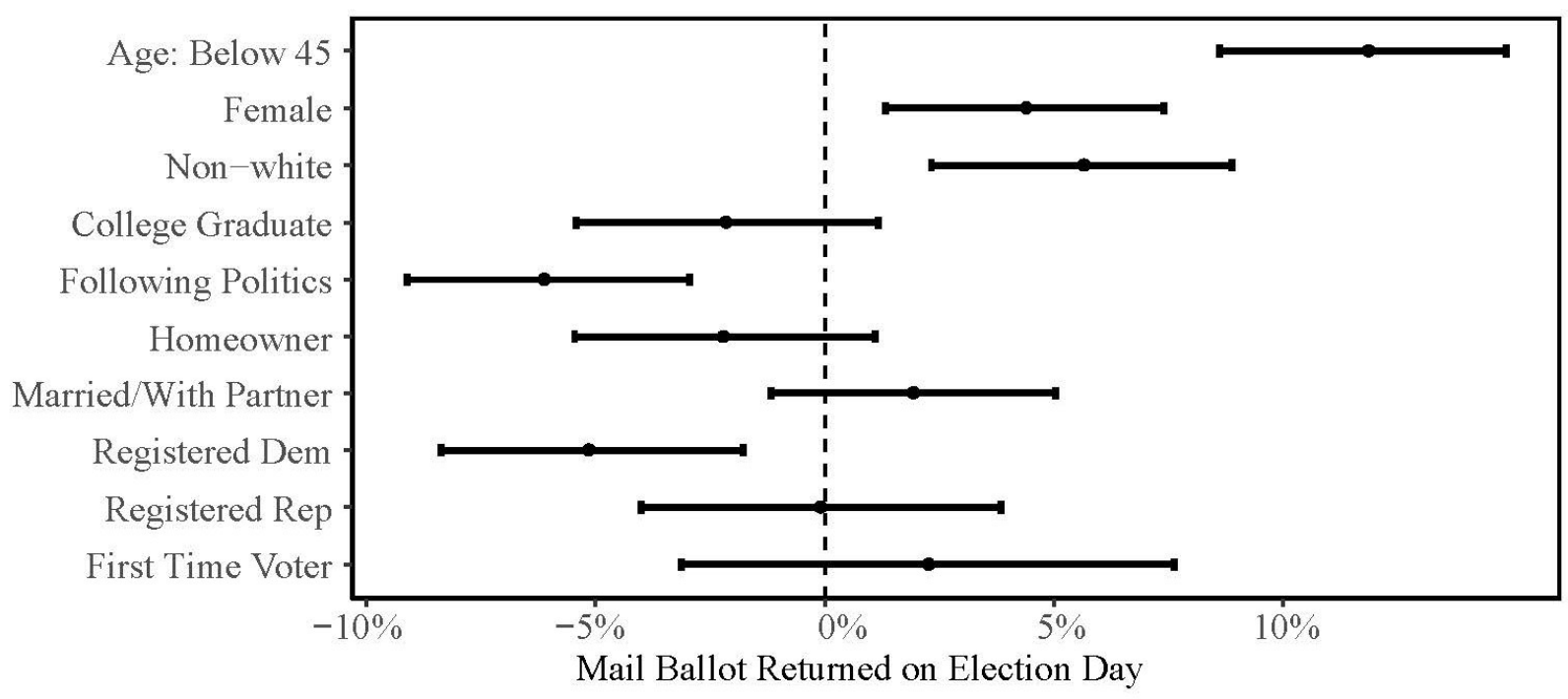

Note: The figure reports average marginal effect estimates and $95 \%$ confidence intervals from logistic regressions, with survey weights incorporated $(\mathrm{N}=3,840$ voting-by-mail voters). The outcome variable is an indicator of whether a voter returned their mail ballot on Election Day (instead of earlier). Independent variables include whether a voter is below the age of 45, is female, is non-white, has a four-year college degree, follows politics, owns their home, is married or lives with their partner, registered with the Democratic party, registered with the Republican party, is a first-time Orange County voter, as well as Congressional district fixed effects. See Online Appendix Table A3 for the results in a table format. 
Figure 8: Association Between Voter Characteristics and Casting Types of Ballots Counted Later in the Process

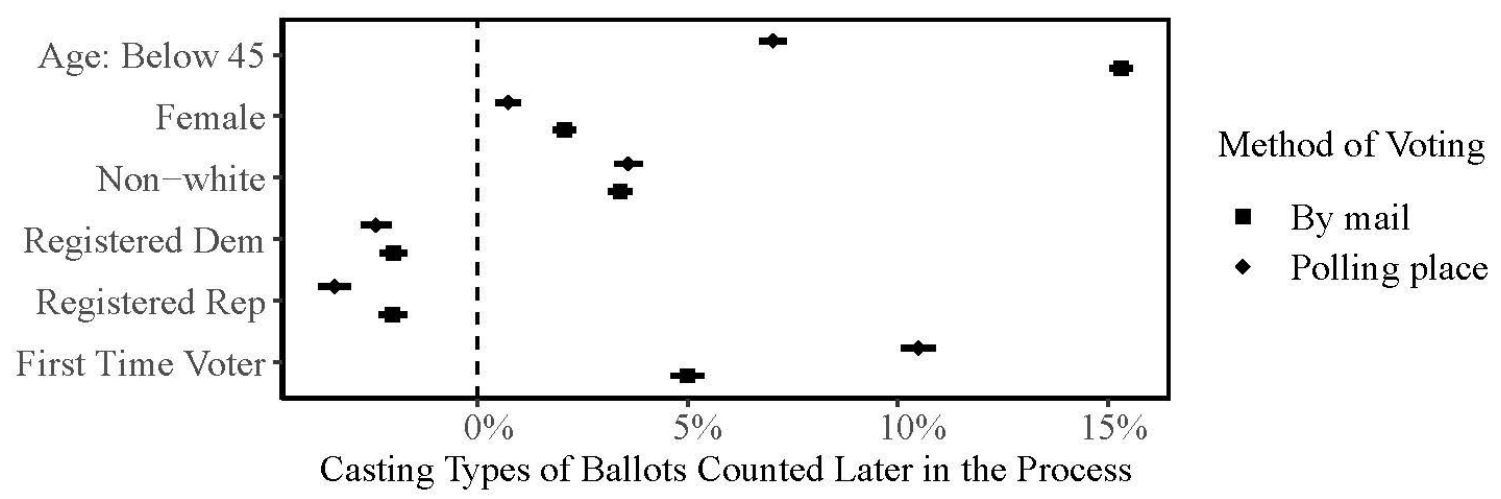

Note: The figure reports average marginal effect estimates and 95\% confidence intervals from logistic regressions $(\mathrm{N}=683,930$ by-mail voters and $\mathrm{N}=379,775$ in-person voters). The outcome variable is an indicator of whether a voter cast types of ballots counted later in the process according to snapshots of the Orange County voting history database. Independent variables include whether a voter is below the age of 45 , female, non-white, registered with the Democratic party, registered with the Republican party, is a first-time Orange County voter, as well as Congressional district fixed effects. See Online Appendix Table A4 for the results in a table format. 
Figure 9: Association Between Voter Characteristics and Returning Mail Ballots Close to Election Day in North Carolina and Colorado

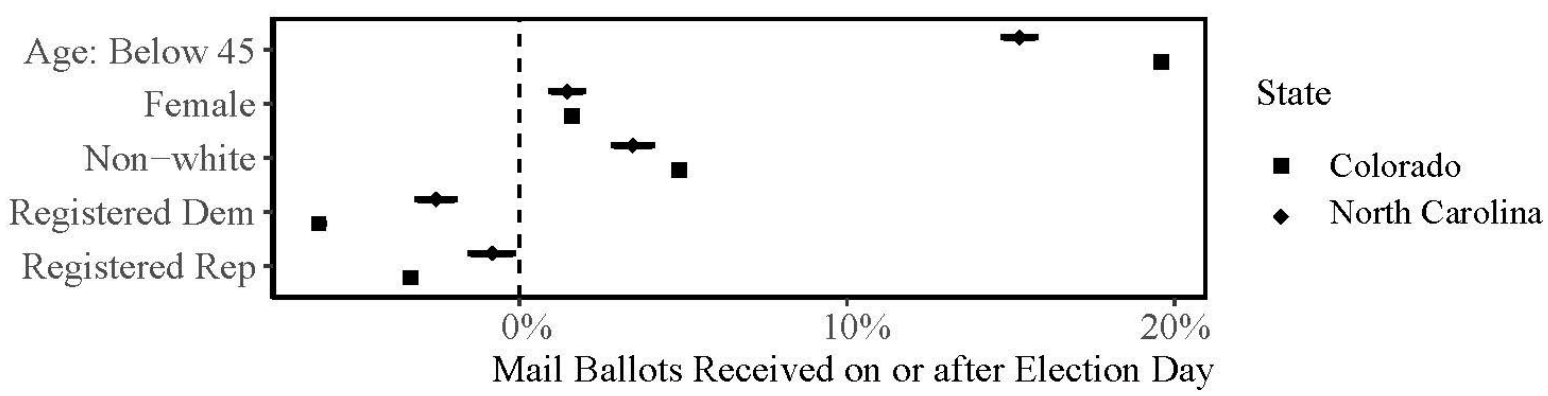

Note: The figure reports average marginal effect estimates and $95 \%$ confidence intervals from logistic regressions $(\mathrm{N}=97,571$ voting-by-mail voters in North Carolina and $\mathrm{N}=2,436,226$ voting-by-mail voters in Colorado). The outcome variable is an indicator of whether a voter's returned mail ballot was received on or after Election Day (instead of earlier). Independent variables include whether a voter is below the age of 45, female, non-white, registered with the Democratic party, registered with the Republican party, as well as Congressional district fixed effects. See Online Appendix Table A5 for the results in a table format. 


\section{Notes}

${ }^{1}$ We obtained the vote shares for the 2018 U.S. House elections from snapshots of the New York Times election results pages captured by Internet Archive's Wayback Machine. The vote shares in the morning after Election Day are extracted from the snapshot at 10:04 am Eastern Time, November 7, 2018. Vote shares reported on the New York Times election results pages are rounded to the closest one-tenth of a percentage point.

${ }^{2}$ https://www.latimes.com/politics/la-me-pol-walters-kim-fraud-claims-20181115-story.html, retrieved on November 3, 2019.

${ }^{3}$ Udani and Kimball (2018) noted that "beliefs about widespread voter fraud have filtered across the American mass public, despite evidence that voter fraud occurs very rarely."

${ }^{4}$ Past research has shown that voter confidence is positively associated with voter participation

(Alvarez, Hall and Llewellyn, 2008).

${ }^{5}$ https://thehill.com/homenews/house/418880-ryan-casts-doubt-on-bizarre-california-election-results, retrieved on November 3, 2019.

${ }^{6}$ For details, see Section 1 in the Online Appendix.

${ }^{7}$ https://www.sos.ca.gov/elections/official-canvass/, retrieved on November 3, 2019.

${ }^{8}$ https://leginfo.legislature.ca.gov/faces/billNavClient.xhtml?bill'id=201320140SB29, retrieved on November 3, 2019.

${ }^{9}$ https://www.ocvote.com/feeds/getNewsletter.php?id=61, retrieved on November 3, 2019.

${ }^{10} \mathrm{https} / / /$ www.ocvote.com/stayconnected/news/election-newsfeeds/, retrieved on November 3, 2019.

${ }^{11}$ https://www.sos.ca.gov/elections/official-canvass/, retrieved on November 3, 2019.

${ }^{12}$ https://www.sos.ca.gov/elections/voting-resources/provisional-voting/, retrieved on November 3, 2019.

13 https://www.ocvote.com/feeds/getNewsletter.php?id=61, retrieved on November 3, 2019; https://elections.cdn.sos.ca.gov/statewide-elections/2018-general/provisional-statistics.pdf, retrieved on March 7,2021.

${ }^{14}$ https://www.sos.ca.gov/administration/news-releases-and-advisories/2018-news-releases-andadvisories/polls-are-closed-californiawhat-expect-during-vote-counting/, retrieved on November 3, 2019.

${ }^{15} \mathrm{https} / / /$ www.ocvote.com/feeds/getNewsletter.php?id=62, retrieved on November 3, 2019.

${ }^{16}$ While provisional ballots make up the vast majority of polling place ballots that are counted after Election Day, some other types of polling place ballots also take longer to count. These include damaged ballots (paper ballots where the barcode has been compromised in some way), unscanned ballots (ballots that did not scan on the first pass), and orphan ballots (ballots that were returned not in full). We use the term polling place ballots counted later in the process (or after Election Day) in our analysis to be accurate.

${ }^{17}$ One special category of voters with extended deadlines are Uniformed and Overseas Citizens Absentee Voting Act (UOCAVA) voters. Ballots cast by UOCAVA voters, however, only make up a very small fraction of all ballots. Moreover, in the case of Orange County, most UOCAVA voters received their ballots by email and cast their ballots via a secure portal (meaning these ballots would have been received before or on Election Day). In 2018, a total of 2,742 
UOCAVA voters participated in the general election in Orange County, 1,936 of whom by email and secure portal.

${ }^{18}$ These two conditions are necessary and sufficient for a large shift in vote shares after Election Day. For such vote share shift to alter the winner of an election, the election also needs to be close. As shown in Figure 1, most shifts in the U.S. House elections in November 2018 are within $6 \%$.

${ }^{19} 0.43 \%$ of 2016 CCES respondents below the age of 45 reported casting provisional ballots, compared to $0.16 \%$ of respondents older than $45.0 .47 \%$ of non-white 2016 CCES respondents reported casting provisional ballots, compared to $0.19 \%$ white respondents.

${ }^{20}$ For additional discussion about the use of administrative data in our analysis, please see the Online Appendix.

${ }^{21}$ We dropped special precincts that are exclusively voting by mail. These precincts are very small, with a median of one and a mean of 45 registered voters in November 2018.

${ }^{22}$ Foley (2013) and Foley and Stewart III (2020) used the vote counts reported in the New York Times on the Thursday following Election Day in the calculation of vote share shifts, as they "serve as a proxy for the best information the candidates had at the point they had to decide whether to concede defeat, declare victory, or demand a recount" (Foley and Stewart III, 2020). We believe the vote counts by the end of Election Night are the more relevant quantities for media coverage and public perceptions.

${ }^{23}$ When not provided, we infer a voter's gender using the R gender package (Mullen, 2018) and a voter's race/ethnicity using the R wru package (Imai and Khanna, 2016). Details are provided in the paper's Supplemental Material.

${ }^{24}$ Regrettably, we did not ask for in-person voters whether they voted provisionally. The administrative records that we described below, however, allow us to study in-person voters as well as voting-by-mail voters.

${ }^{25}$ Here we use the identifier OCROV included in their database. An alternative methodology for record linkage for applications like ours can be found in Enamorado, Fifield and Imai (2019) and Kim, Schneider and Alvarez (2019).

${ }^{26}$ Our data at hand, unfortunately, do not allow us to uncover the mechanism behind this result, which warrants future research. A larger proportion of registered Democratic voters could be correlated with variables that are not contained in the administrative records, ultimately leading to a larger "Blue Shift." This is also likely the reason for bluer states, on average, having a larger "Blue Shift" in 2012 reported in Foley and Stewart III (2020).

${ }^{27}$ A majority of voters in North Carolina cast absentee ballots in person during the early voting period in 2018.

${ }^{28} \mathrm{https} / / /$ www.eac.gov/documents/2017/10/17/eavs-deep-dive-early-absentee-and-mail-voting-data-statutoryoverview; https://electionlab.mit.edu/research/voting-mail-and-absentee-voting.

${ }^{29}$ For example, see the U.S. Supreme Court decision from the Wisconsin case in Republican National Committee, et al. v. Democratic National Committee, et al., 2020. 


\section{Supplemental Material}

for

Why Do Election Results Change After Election Day?

The "Blue Shift" in American Elections 


\section{Vote Share Shift in 2020 Presidential Election in PA}

Figure A1: Vote Shares in 2020 Presidential Election in PA as Ballots Were Counted
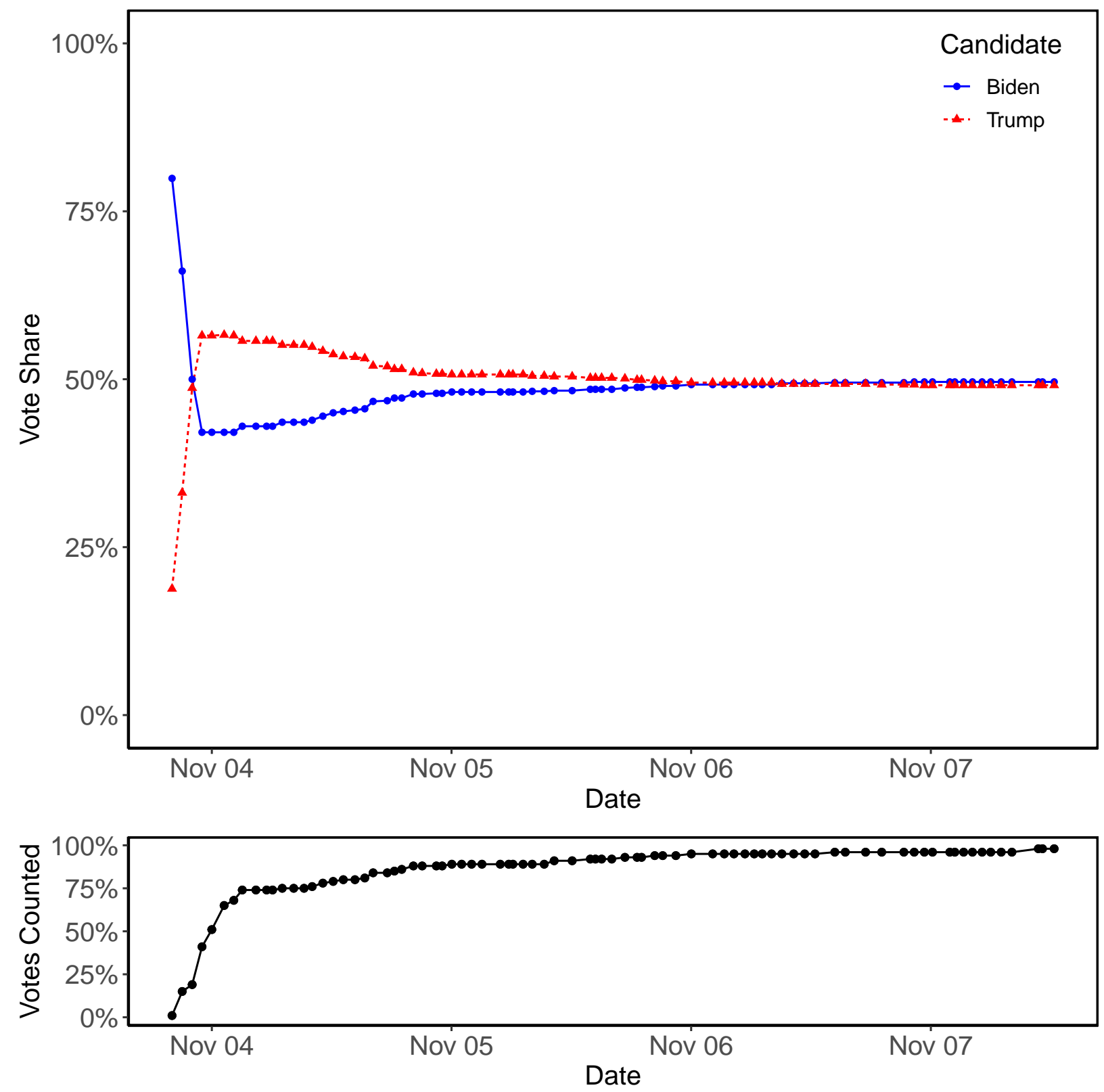

\section{Administrative Data}

We make use of administrative data in some of the key analyses in our paper, and as some readers may not be familiar with administrative data like this, here we provide some details about the quality 
and accuracy of these data.

Currently in the United States, per the requirements of the Help America Vote Act (HAVA, 2002), states like California are required to have statewide voter registration databases. The maintenance of these databases, though, is regulated by the earlier National Voter Registration Act (NVRA, 1993). California's NVRA regulations are specified by the California's Secretary of State (https : / / www . sos.ca.gov/elections/voter-registration/nvra/laws-standards/nvra-manual). Specifically, these detailed regulations govern the process by which potentially ineligible voters (usu-

ally because of death or change of residence) can be moved to inactive status or removed from the file. Orange County, whose administrative data we use in this paper, has for quite some time used a variety of innovative and proactive methodologies to develop as accurate a list as possible (https : / / www . ocvote.com/registration/maintaining-an-accurate-voter-list).

As has been noted in recent research using these administrative data from Orange County ?, in a jurisdiction of this size, there will be record changes, new records, and removed records. However, this recent research has shown that these changes in the administrative data are relatively small in relation to the overall file, and there is no research that we are aware of that would indicate that file maintenance or inaccuracies in the administrative data more generally should have any effect on our estimate of the quantities we examine in our paper.

\section{Details about The 2018 Survey of Registered Voters}

In California, voters can provide contact information (like a telephone number or email address) when they register to vote. Of the approximately 1.6 million voter registration records in the County in the 2018 general election, over 500,000 of those records were associated with an email address. In association with the Orange County Registrar of Voters (OCROV), we built a self-completion online survey aimed to evaluate voter experience in the November 2018 General Election. We invited registered voters (via email) to participate in our voter experience survey between Thursday, 


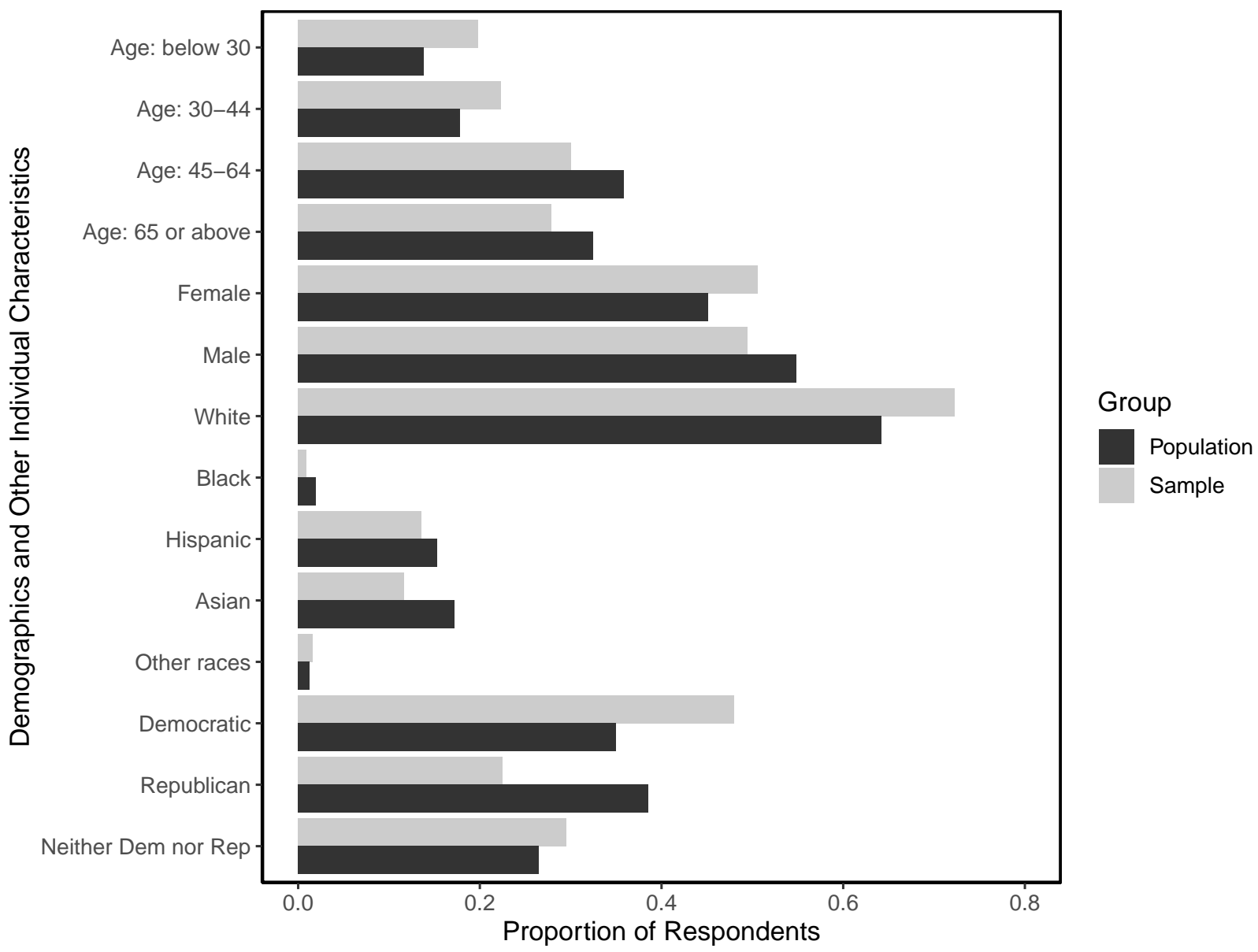

Figure A2: Respondent Composition of the Survey

November 8, 2018 and Tuesday, November 13, 2018. From 531,777 invites to all registered voters with email addresses, we received 6,952 complete responses (response rate: $1.3 \%$ ). The survey took about 12 to 15 minutes to compete (the median duration was 13 minutes) and was provided in English.

Figure A2 displays a number of the important demographic and administrative features of our survey respondents who voted by mail, and for the population of Orange County voters who participated in the November 2018 General Election by mail. Younger voters are somewhat over-represented in our survey sample, with $6.0 \%$ and $4.5 \%$ more respondents below the age of 30 and between the age of 30 and 44, respectively, compared to the population of voters. Female voters and white voters are also somewhat over-represented in our survey sample, by $5.4 \%$ and $8.0 \%$, respectively. 
Our survey sample exhibits additional imbalances in party registration. While $38.5 \%$ of voters who turned out in the November 2018 General Election by mail registered with the Republican party in Orange County, only $22.5 \%$ of those by-mail voters who completed our survey are Republican voters. On the other hand, $48.0 \%$ of respondents who voted by mail registered with the Democratic party, compared to $35.0 \%$ in the population of by-mail voters. The disparities in terms of party registration present in our survey sample are expected given our knowledge about survey participation in general and consistent with other surveys with voluntary participation. The distribution of cities of residence for our sample tracks the population well.

Given the disparities in terms of some demographics and registration characteristics, to make our analysis representative of Orange County registered voters, it's necessary to construct survey weights and incorporate them in our analysis. We use a standard calibration weighting procedure known as raking. Our raking algorithm matches sample moments on age, gender, race/ethnicity, party registration, and city of residence to their population counterparts, to produce weights that we use in our statistical analyses to produce representative results. These survey weights are incorporated into the results we reported in this paper.

\section{Details about Gender and Race/Ethnicity for Administration Records}

To determine the gender of a voter in the administrative records in Orange County (CA), North Carolina, and Colorado, we use (in descending order of priority) (1) voter provided gender, (2) voter provided title (Mr., Mrs., Miss., Ms.), (3) inferred probability from first name, or (4) inferred probability from middle name. To determine the race/ethnicity of a voter, we use (1) voter provided race/ethnicity (only available in North Carolina), or (2) inferred probability of being non-Hispanic white from last name. Aggregating the gender and race information/probabilities yields our precinct percentages of voters below the age of 45 and nonwhite voters. For our individual-level analysis, 
we code a voter as female/male if we know from the voter provided gender or infer with probability at least $90 \%$. We code a voter as a non-Hispanic white if we know from the voter provided race or infer so with probability at least $80 \%$. Our results are robust to tightening or loosening these thresholds.

\section{Summary of Hypotheses}

- Hypothesis 1: Hypotheses regarding volume of different type of ballots:

- Hypothesis 1a: Precincts with a larger percentage of polling place ballots that are counted later in the process on average have a larger "Blue Shift" after Election Day.

- Hypothesis 1b: The percentage of permanent absentee voters in a precinct is not correlated with the magnitude of the "Blue Shift", but precincts with a larger percentage of mail ballots that are counted later in the process on average have a larger "Blue Shift" after Election Day.

- Hypothesis 2: Hypotheses regarding individual voter characteristic:

- Hypothesis 2a: Young and non-white voters are more likely to cast polling place ballots that are counted later in the process.

- Hypothesis 2b: Young and non-white voters are more likely to cast mail ballots that are counted later in the process.

- Hypothesis 2c: Voters registered with the two major parties are less likely to cast polling place or mail ballots that are counted later in the process.

- Hypothesis 3: Hypotheses regarding precinct voter composition:

- Hypothesis 3a: Precincts with a larger percentage of young voters and non-white voters 
on average have a larger "Blue Shift" after Election Day.

- Hypothesis 3b: Precincts with a larger percentage of registered Democratic (Republican) voters on average have a smaller (larger) "Blue Shift" after Election Day.

- Hypothesis 3c (alternative hypothesis to $\mathbf{3 b}$ ): Precincts with a larger percentage of registered Democratic (Republican) voters on average have a larger (smaller) "Blue Shift" after Election Day.

\section{The Blue Shift in Orange County, California (House of Rep- resentatives)}

Figure A3: Vote Share Shifts as Canvass Progresses, Orange County, November 2018 (House of Representatives)

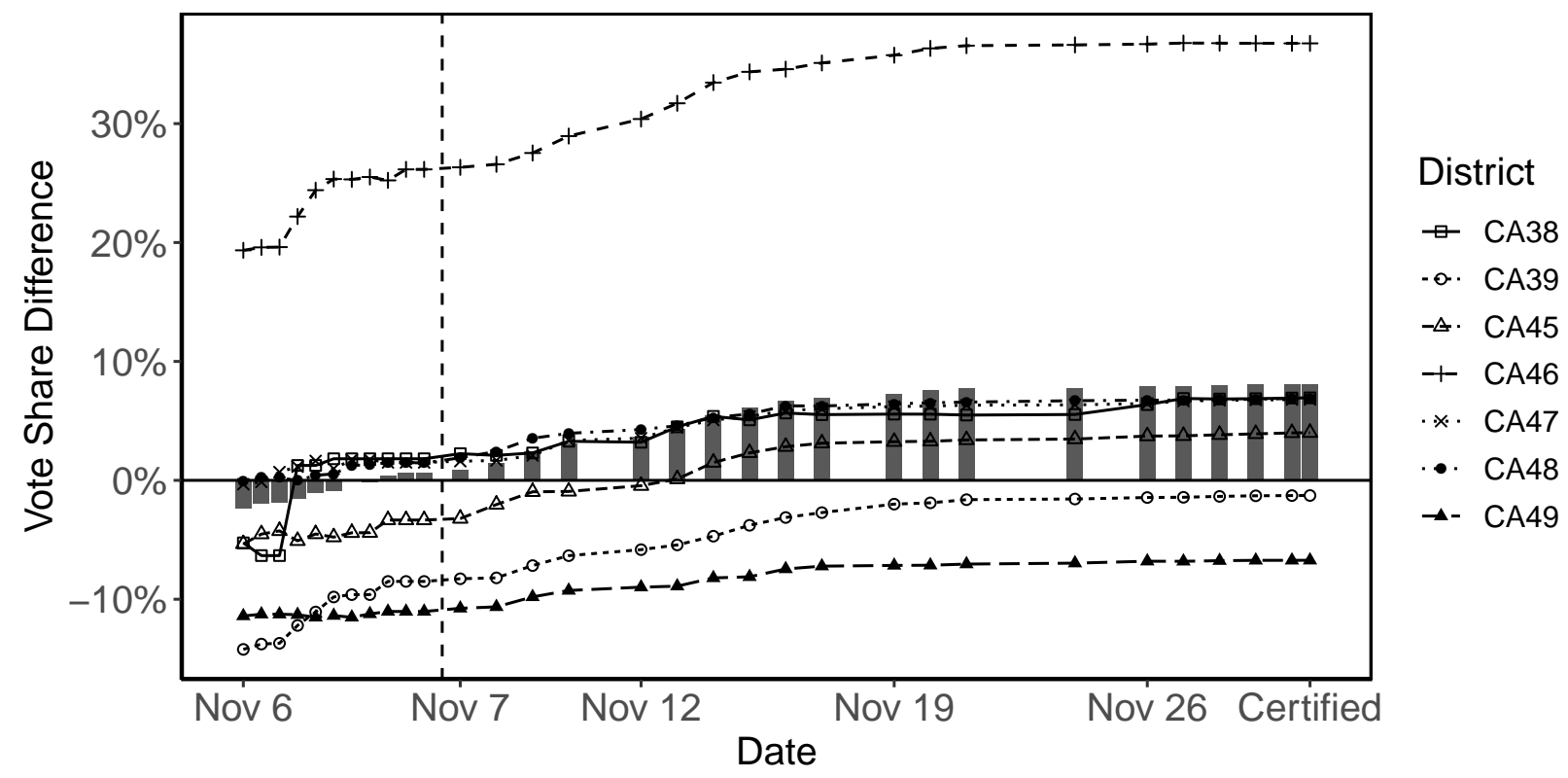

Note: The figure reports the vote share differences (Democratic vote share minus Republican vote share) at different points during the canvass at county level (bars) and district level (lines and points), for the U.S. House of Representatives races in Orange County in the November 2018 General Election. 
Figure A4: Election Night Final and Certified Precinct Vote Share Differences, Orange County, November 2018 (House of Representatives)

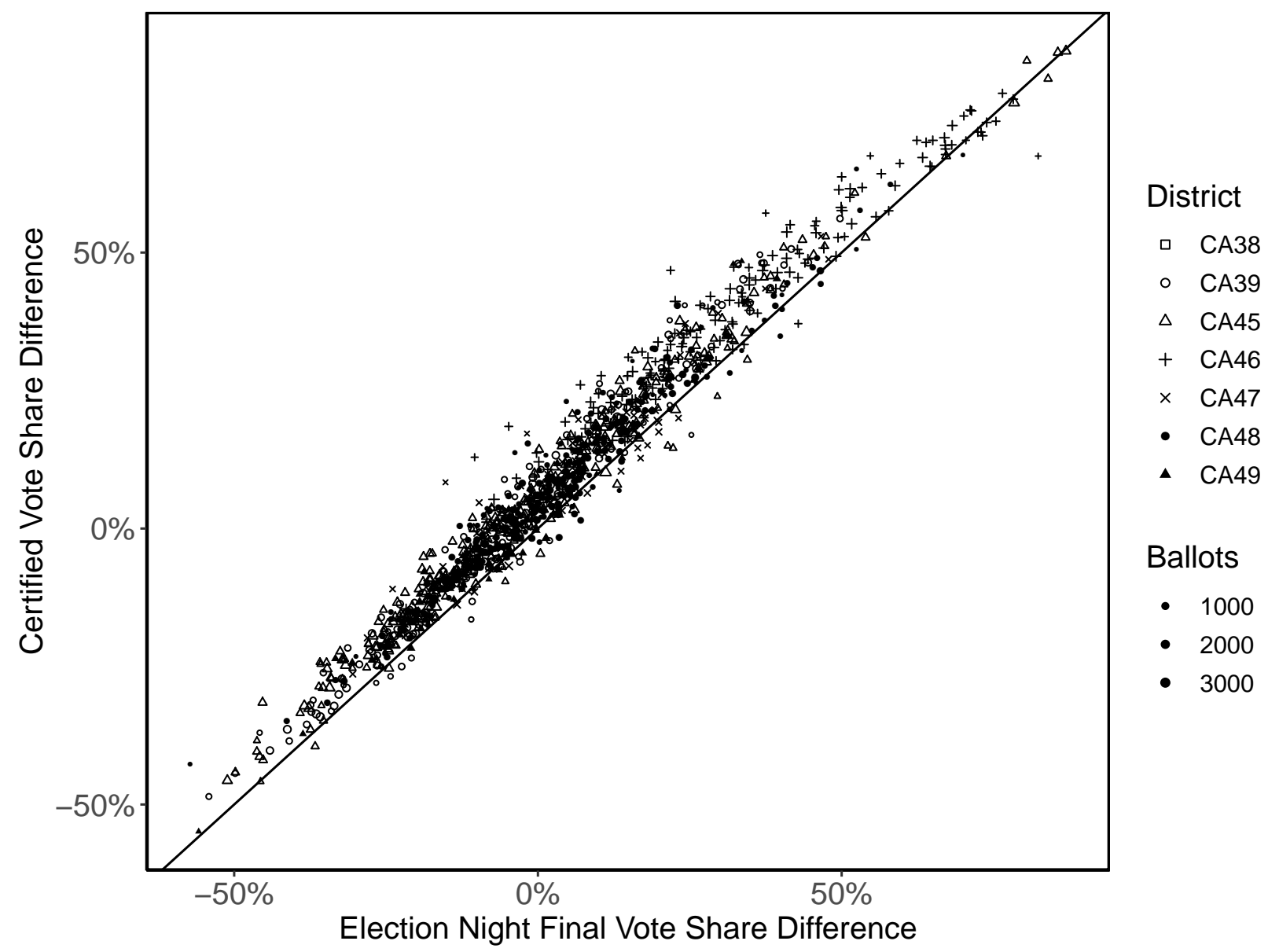

Note: The figure reports the precinct-level vote share differences (Democratic vote share minus Republican vote share) by the end of Election Night and the canvass, for the U.S House of Representatives races in Orange County in the November 2018 General Election. Sizes of the points and other shapes are proportional to the number of ballots cast. 


\section{Precinct-Level Analysis: Volume of Ballots Counted After}

\section{Election Day}

Table A1: Fraction of Mail and Polling Place Ballots Counted After Election Day and Precinct Vote Share Shift

\begin{tabular}{lcccc}
\hline & Governor & SE & House & SE \\
\hline Intercept & 0.032 & 0.004 & 0.039 & 0.004 \\
Mail Ballots & 0.055 & 0.014 & 0.025 & 0.013 \\
Polling Place Ballots & 0.054 & 0.012 & 0.059 & 0.011 \\
\hline N & \multicolumn{2}{c}{1115} & 1115 \\
Adj. R-squared & 0.029 & 0.026 \\
\hline
\end{tabular}

Figure A5: Fraction of Mail and Polling Place Ballots Counted After Election Day and Precinct Vote Share Shift

$$
y=0.041+0.057 x
$$

(0.004) (0.014)

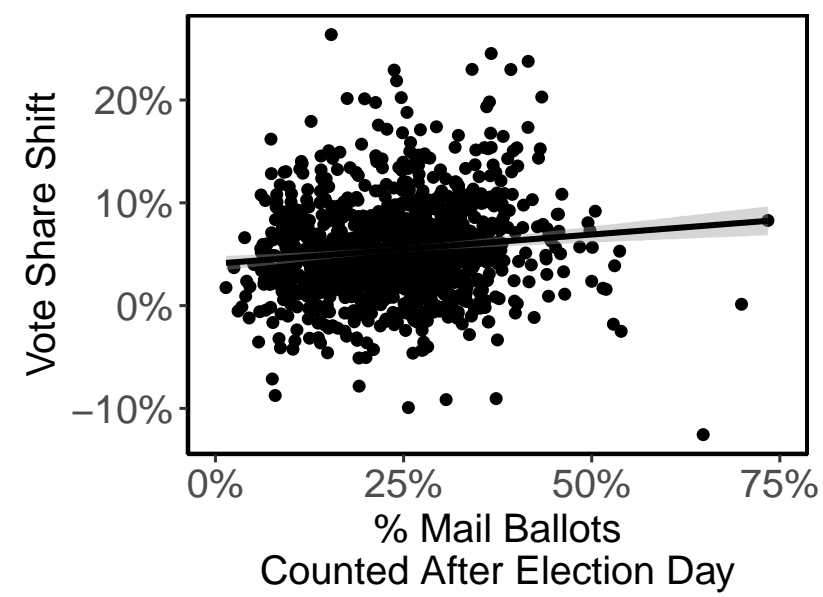

$y=0.045+0.055 x$

$(0.003) \quad(0.012)$

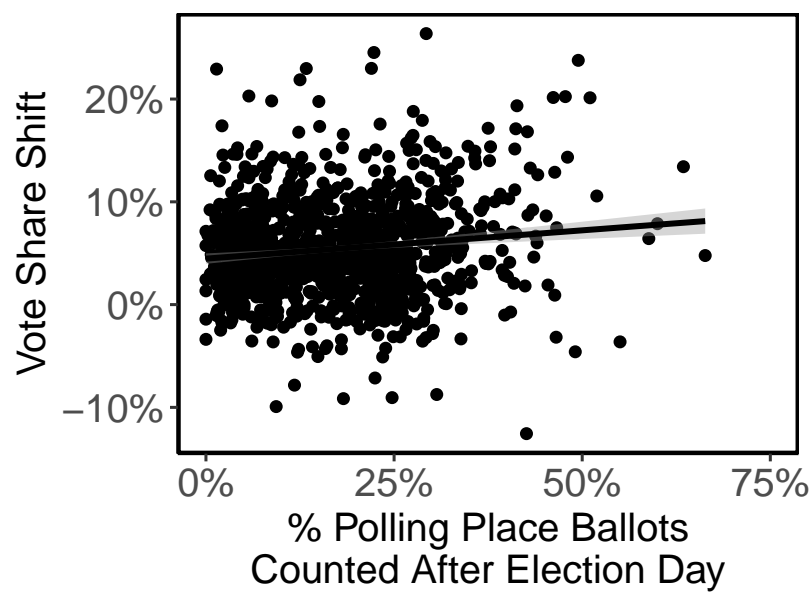

Note: These scatterplots display the relationships between precinct vote share shifts and fractions of mail and polling place ballots counted after Election Day, respectively $(\mathrm{N}=1,115$ precincts). Solid lines and shaded areas correspond to fitted least squares and $95 \%$ confidence intervals.

\section{Precinct-Level Analysis: Volume of Mail Ballots Counted Af-} ter Election Day and Percent of Permanent VBM Voters 
Figure A6: Volume of Mail Ballots Counted After Election Day and Percent of Permanent VBM Voters

$$
y=0.342-0.148 x
$$

$(0.041) \quad(0.060)$

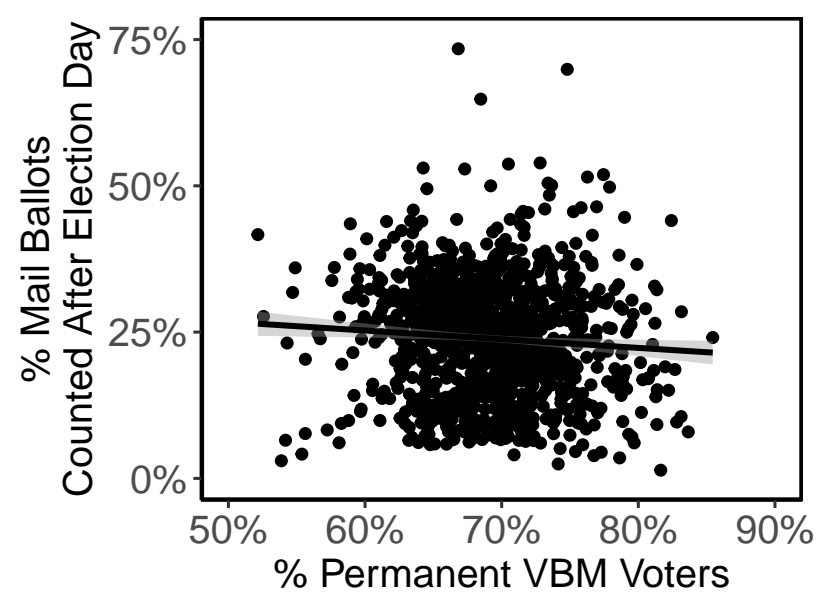

Note: The scatterplot displays the relationship between the fraction of mail ballots counted after Election Day and the percent of permanent vote-by-mail voters at precinct level ( $\mathrm{N}=1,115$ precincts). Solid lines and shaded areas correspond to fitted least squares and $95 \%$ confidence intervals. 


\section{Precinct-Level Analysis: Voter Composition}

Table A2: Association between Voter Composition and Precinct Vote Share Shift

\begin{tabular}{lcccc}
\hline & \multicolumn{2}{c}{ 2018 General } & \multicolumn{2}{c}{ 2016 General } \\
& Estimate & SE & Estimate & SE \\
\hline Age: Below 45 & 0.046 & 0.019 & 0.033 & 0.012 \\
Female & -0.075 & 0.057 & 0.009 & 0.036 \\
Non-white & 0.093 & 0.013 & 0.045 & 0.009 \\
Registered Dem & 0.146 & 0.042 & 0.095 & 0.028 \\
Registered Rep & 0.184 & 0.041 & 0.118 & 0.027 \\
Permanent VBM & -0.017 & 0.031 & -0.022 & 0.019 \\
\hline Cong. District FE & \multicolumn{2}{c}{ Included } & Included \\
N & \multicolumn{2}{c}{1115} & 1365 \\
Adj. R-squared & \multicolumn{2}{c}{0.646} & \multicolumn{3}{c}{0.349} \\
\hline
\end{tabular}




\section{Precinct-Level Analysis: Voter Composition (House of Rep-}

\section{resentatives)}

Figure A7: Association between Voter Composition and Precinct Vote Share Shift (House of Representatives)

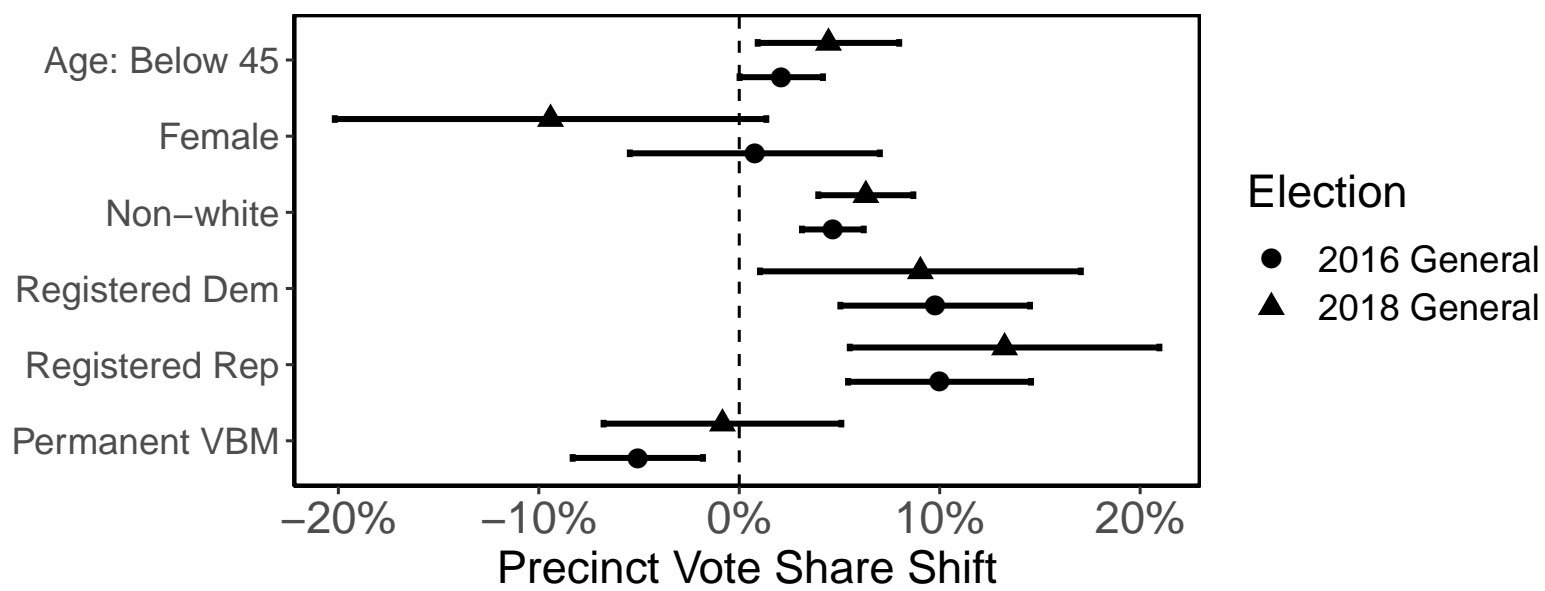

Note: The figure reports coefficient estimates and 95\% confidence intervals from linear regressions. Precinct vote share shifts are defined as the changes between the last run during Election canvass and the last run on Election night in precinct-level vote share differences (Democratic candidate vote share minus Republican candidate vote share). Independent variables include the proportion of voters in a precinct who are of age below 45, female, non-white, registered with the Democratic party, registered with the Republican party, and signed up for permanent vote-by-mail ballots, as well as Congressional district fixed effects. 


\section{Voter-Level Analysis: Voter Survey}

Table A3: Association between Voter Characteristics and Returning Mail Ballots on Election Day: Voter Survey (Logistic Regressions with Survey Weights)

\begin{tabular}{lcccc}
\hline & Estimate & SE & AME & SE \\
\hline Age: Below 45 & 0.780 & 0.111 & 0.119 & 0.016 \\
Female & 0.289 & 0.101 & 0.044 & 0.016 \\
Non-white & 0.372 & 0.108 & 0.057 & 0.017 \\
College Graduate & -0.141 & 0.111 & -0.021 & 0.017 \\
Following Politics & -0.401 & 0.104 & -0.061 & 0.016 \\
Homeowner & -0.145 & 0.110 & -0.022 & 0.017 \\
Married/With Partner & 0.128 & 0.104 & 0.019 & 0.016 \\
Registered Dem & -0.337 & 0.109 & -0.051 & 0.017 \\
Registered Rep & -0.005 & 0.131 & -0.001 & 0.020 \\
First Time Voter & 0.149 & 0.180 & 0.023 & 0.027 \\
\hline Cong. District FE & \multicolumn{5}{c}{ Included } \\
N & \multicolumn{5}{c}{3840} \\
\hline
\end{tabular}

\section{Voter-Level Analysis: Administrative Records}

Table A4: Association between Voter Characteristics and Casting Types of Ballots Counted Later in the Process (Logistic Regressions)

\begin{tabular}{lcccccccc}
\hline & \multicolumn{4}{c}{ Mail } & \multicolumn{4}{c}{ Polling Place } \\
& Est. & SE & AME & SE & Est. & SE & AME & SE \\
\hline Age: Below 45 & 0.914 & 0.007 & 0.153 & 0.001 & 0.532 & 0.010 & 0.070 & 0.001 \\
Female & 0.123 & 0.006 & 0.021 & 0.001 & 0.055 & 0.009 & 0.007 & 0.001 \\
Non-white & 0.202 & 0.007 & 0.034 & 0.001 & 0.271 & 0.010 & 0.036 & 0.001 \\
Registered Dem & -0.120 & 0.008 & -0.020 & 0.001 & -0.184 & 0.011 & -0.024 & 0.001 \\
Registered Rep & -0.121 & 0.008 & -0.020 & 0.001 & -0.258 & 0.012 & -0.034 & 0.002 \\
First Time Voter & 0.298 & 0.010 & 0.050 & 0.002 & 0.794 & 0.013 & 0.105 & 0.002 \\
\hline Cong. Dist. FE & \multicolumn{4}{c}{ Included } & \multicolumn{5}{c}{ Included } \\
$\mathrm{N}$ & \multicolumn{4}{c}{683,930} & & \multicolumn{5}{c}{379,775} \\
\hline
\end{tabular}




\section{Beyond Orange County California}

Table A5: Association between Voter Characteristics and Returning Mail Ballots close to Election Day in North Carolina and Colorado (Logistic Regressions)

\begin{tabular}{|c|c|c|c|c|c|c|c|c|}
\hline & \multicolumn{4}{|c|}{ North Carolina } & \multicolumn{4}{|c|}{ Colorado } \\
\hline & Est. & SE & AME & $\mathrm{SE}$ & Est. & SE & AME & SE \\
\hline Age: Below 45 & 1.094 & 0.018 & 0.153 & 0.002 & 1.098 & 0.003 & 0.196 & 0.001 \\
\hline Female & 0.104 & 0.018 & 0.015 & 0.002 & 0.089 & 0.003 & 0.016 & 0.001 \\
\hline Non-white & 0.248 & 0.021 & 0.035 & 0.003 & 0.273 & 0.003 & 0.049 & 0.001 \\
\hline Registered Dem & -0.182 & 0.020 & -0.025 & 0.003 & -0.343 & 0.004 & -0.061 & 0.001 \\
\hline Registered Rep & -0.060 & 0.023 & -0.008 & 0.003 & -0.187 & 0.004 & -0.033 & 0.001 \\
\hline Cong. Dist. FE & \multicolumn{4}{|c|}{ Included } & \multicolumn{4}{|c|}{ Included } \\
\hline $\mathrm{N}$ & \multicolumn{4}{|c|}{97,571} & \multicolumn{4}{|c|}{$2,436,226$} \\
\hline
\end{tabular}

